Universidad de Lima

Facultad de Ciencias Empresariales y Económicas

Carrera de Marketing

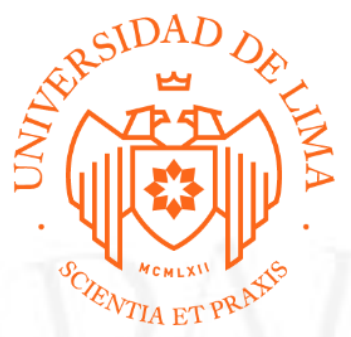

\title{
LANZAMIENTO EN PERÚ DEL SAMSUNG GALAXY S9
}

Trabajo de suficiencia profesional para optar el Título Profesional de Licenciado en Marketing

NICOLAS LANATTA ROSAS

Código 20131928

\author{
Asesor \\ Alfredo José Galdo Jiménez
}

Lima - Perú

noviembre de 2018 


\section{LANZAMIENTO EN PERÚ DEL SAMSUNG GALAXY S9}




\section{INDICE}

INTRODUCCIÓN...................................................................................................1 1

CAPÍTULO I: CONTEXTO DE LA EMPRESA …................................................. 2

1.1 Descripción y antecedentes de la industria en la que se desempeña la empresa. 2

1.2 Descripción de la empresa en cuanto a los accionistas, estructura organizacional, unidades de negocios, marcas y mezcla de productos .................................... 3

1.3 Descripción del mercado y sus segmentos.................................................... 7

1.4 Identificación, descripción y participación de mercado de competidores directos

CAPÍTULO II: DIAGNÓSTICO DEL MARKETING ESTRATÉGICO DE LA

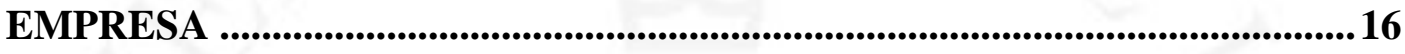

2.1 Descripción y análisis de la estrategia genérica............................................ 16

2.2 Descripción y análisis de la(s) ventaja(s) competitiva(s) ............................. 16

2.3 Descripción y análisis de la(s) estrategia(s) de marketing corporativo que aplica

2.4 Descripción y análisis de la(s) estrategia(s) competitiva(s) de marketing que aplica

2.5 Descripción del(los) grupo(s) objetivo que atiende ..................................... 19

2.6 Descripción del posicionamiento de la empresa o marca(s) ..........................220

2.7 Descripción de la creación del brand equity de su(s) marca(s)......................20

CAPÍTULO III: DESCRIPCIÓN DEL CASO PROBLEMA ..................................23

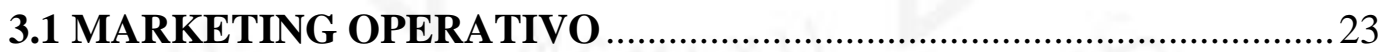

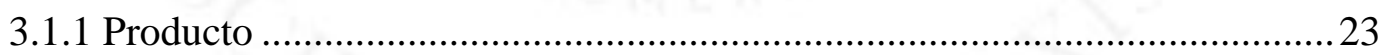

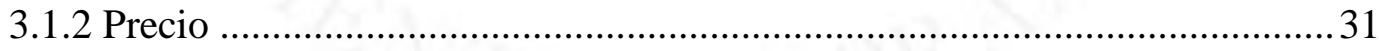

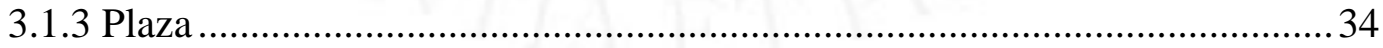

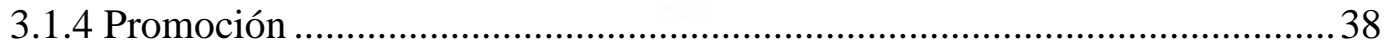

CAPITULO IV: ANÁLISIS Y DISCUSIÓN DE RESULTADOS ...........................46

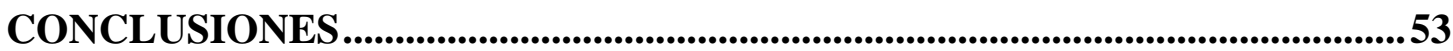

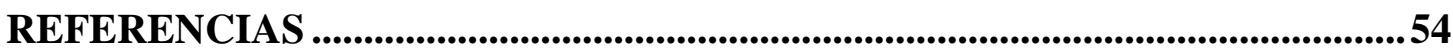

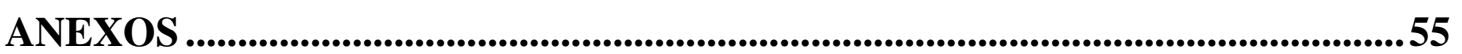




\section{ÍNDICE DE TABLAS}

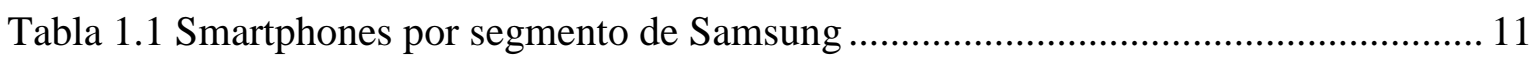

Tabla 1.2 Participación de mercado según exportaciones a nivel mundial ......................... 12

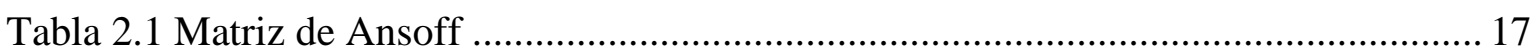

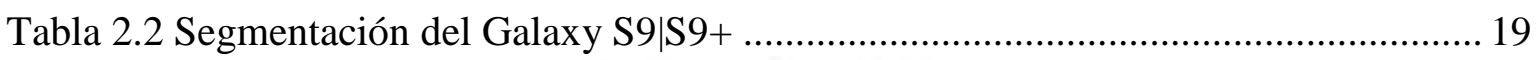

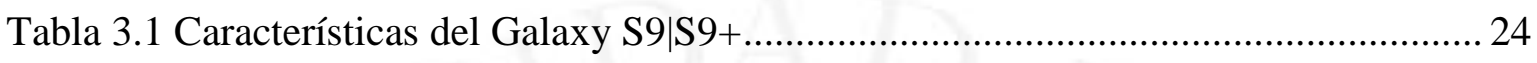

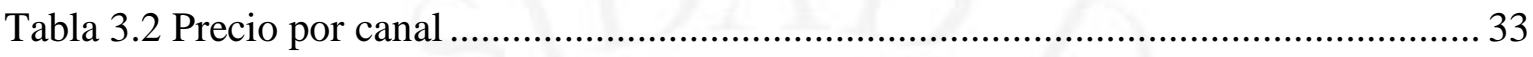

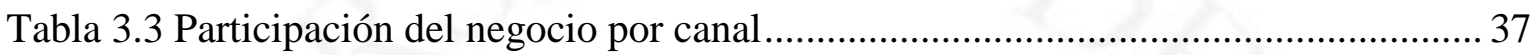

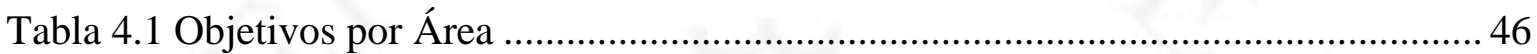

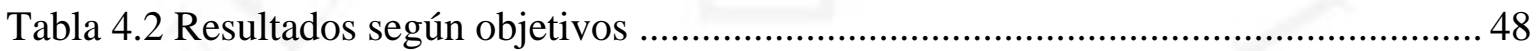




\section{ÍNDICE DE FIGURAS}

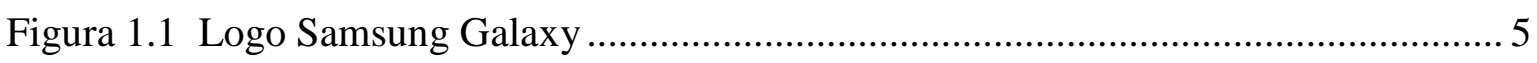

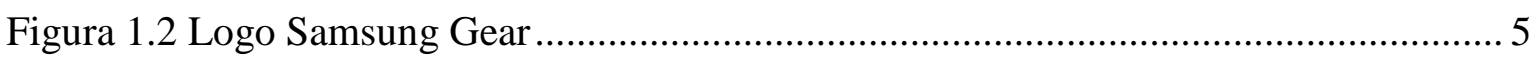

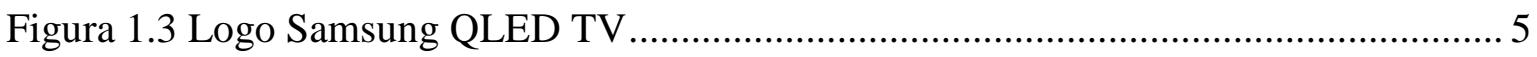

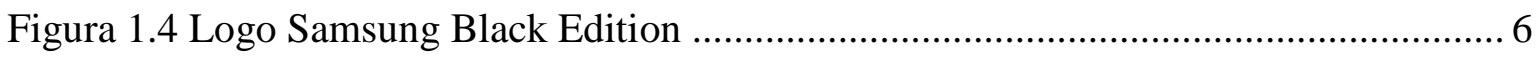

Figura 1.5 Evolución de la tenencia de Smartphone ....................................................... 7

Figura 1.6 Evolución de la tenencia de Smartphone por NSE ......................................... 8

Figura 1.7 Evolución de la tenencia de Telefonía Fija, Celular y Smartphone ..................... 9

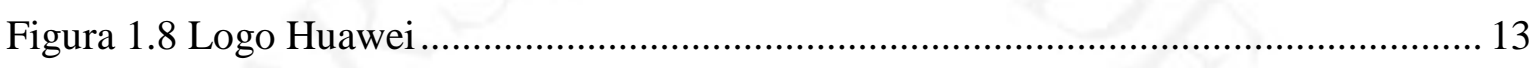

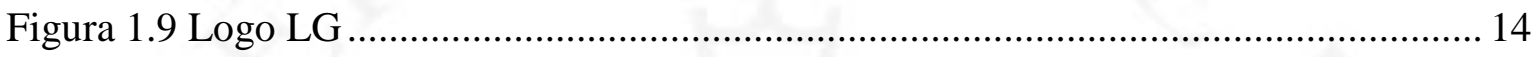

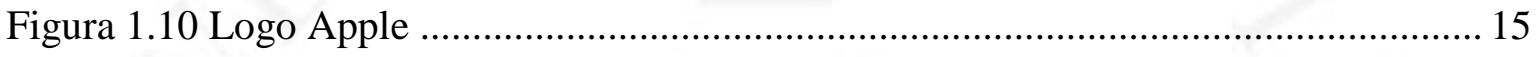

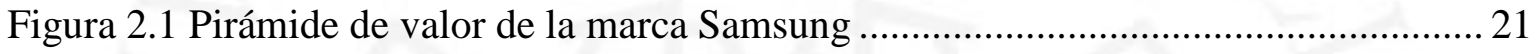

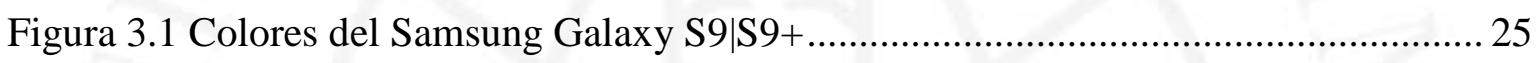

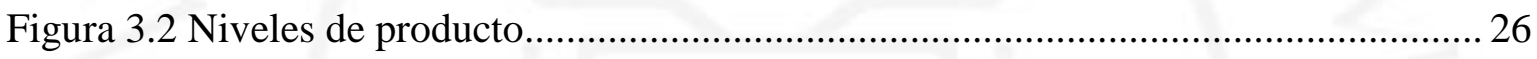

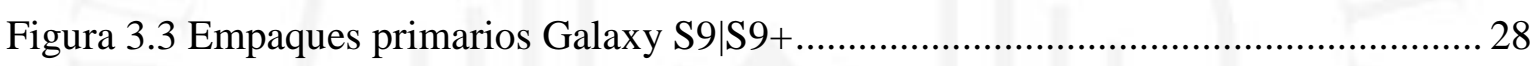

Figura 3.4 Empaques secundarios Empaques primarios Galaxy S9|S9+ _....................... 28

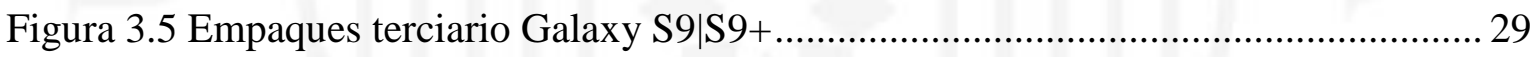

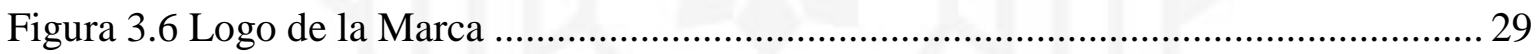

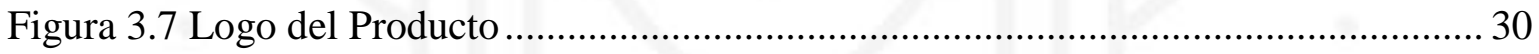

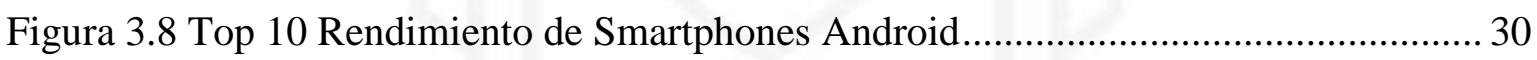

Figura 3.9 Precios de la competencia del Galaxy S9 …................................................. 32

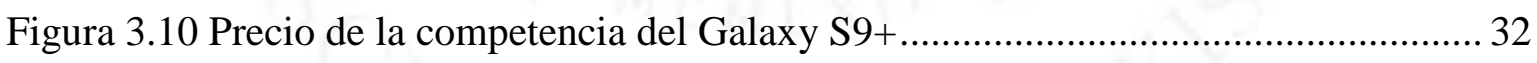

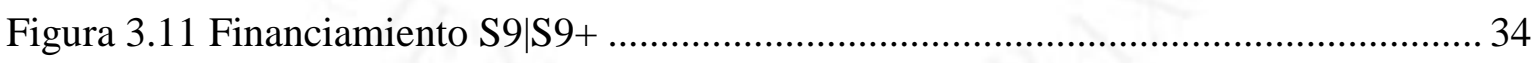

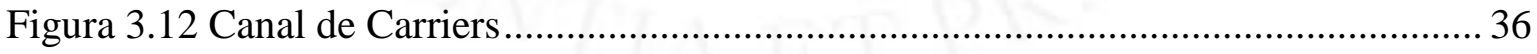

Figura 3.13 Canal de Retailers y Supermercados.............................................................. 36

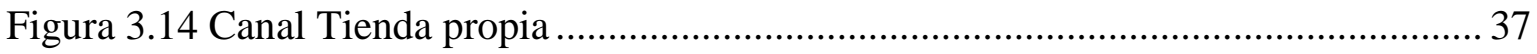

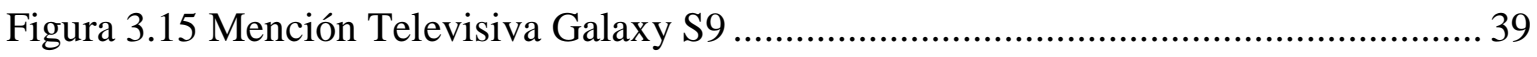

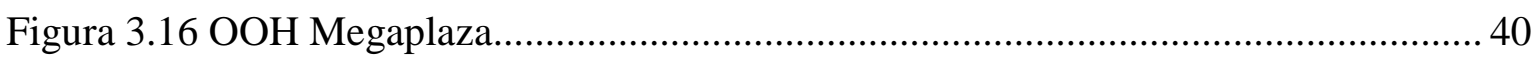

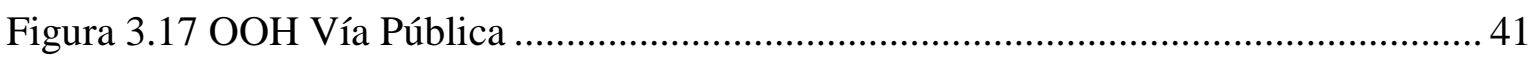

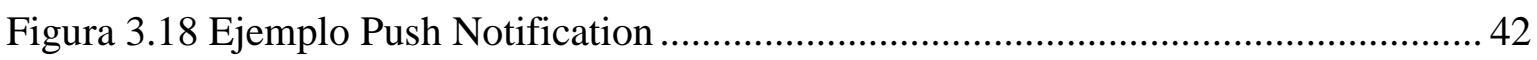

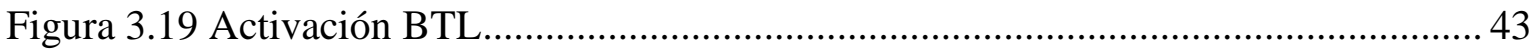

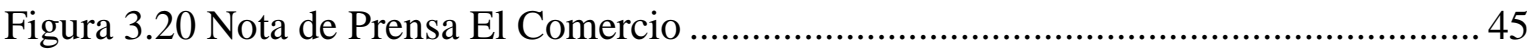




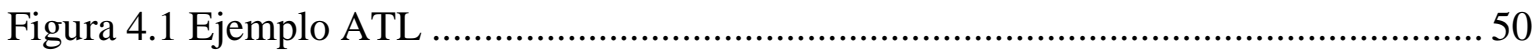

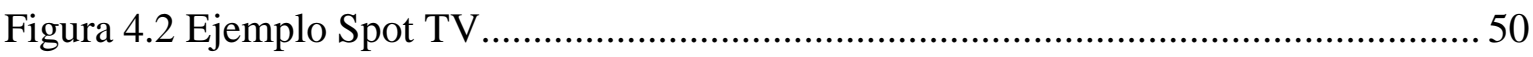

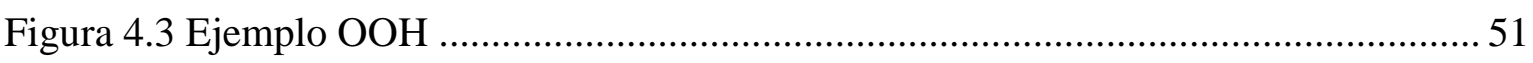




\section{ÍNDICE DE ANEXOS}

Anexo 1. Perfil del Smartphonero realizado por IPSOS 2017 .......................................... 56

Anexo 2 Reporte de Mercado Smartphones por CPI ....................................................... 58 


\section{INTRODUCCIÓN}

Actualmente, el mercado de los Smartphones es un mercado que viene creciendo exponencialmente en el Perú. La necesidad de los consumidores de contar con Internet en sus celulares, está cambiando las tendencias hacia celulares inteligentes. Según Perú Retail, en el 2017 la penetración de los smartphones era del 33\% con 12,7 millones de unidades. Esto significa una gran oportunidad para las empresas comercializadoras de Smartphones.

En el siguiente caso de estudio se analizara el lanzamiento del Galaxy S9|S9+ de Samsung en el Perú y la estrategia de Marketing Operativo que se utilizó.

Samsung es una marca reconocida y líder a nivel mundial y en el Perú. Sin embargo, actualmente empresas como Huawei, LG y Apple quieren aprovechar el bajo nivel de penetración para desarrollar la demanda y seguir creciendo.

El celular se lanzó mundialmente en marzo y llego a Perú en abril. Sin embargo la campaña empezó la segunda mitad de marzo. Con el pre-registro, para los usuarios interesados en el producto y la pre-venta.

La estrategia de producto se centra en la calidad y en las características superiores del Galaxy S9, frente a su competencia. El precio está dentro de los estándares de los celulares de gama alta, por encima de los precios de Huawei y por debajo de los de Apple. Los canales de distribución para el producto, fueron los que se usa actualmente Samsung, los Carriers u Operadores, los Retailers/Supermercados y las cinco tiendas propias con las que cuenta la marca en Perú. Se utilizaron todos los elementos de la mezcla de promoción, para comunicar el lanzamiento y las características del celular.

La campaña tuvo resultados positivos, sin embargo hubo diferencias entre las unidades proyectadas a vender y las que efectivamente se vendieron. El modelo S9+ excedió lo proyectado y el S9 no llego a venderse por completo. Del mismo modo los modelos de color morado, tuvieron un mejor desempeño de ventas que los modelos negros y grises. 


\section{CAPÍTULO I: CONTEXTO DE LA EMPRESA}

\subsection{Descripción y antecedentes de la industria en la que se desempeña la empresa.}

La Empresa Samsung Electronics Peru SAC opera en nuestro país desde al año 1996. Samsung Perú es una filial de la multinacional coreana Samsung, el mayor grupo empresarial del país asiático. A nivel mundial tienen negocios que abarcan la electrónica de consumo, tecnología, publicidad, aseguradoras, finanzas, construcción, servicios...etc. Sin embargo, en el mercado peruano solo tienen dos de estas unidades de negocio, parte de electrónica de consumo. Mobile y Consumer Electronics.

Consumer Electronics se divide en dos categorías TV's y Digital Appliances (Línea Blanca), en el caso de Línea Blanca cuenta con cuatro sub-divisiones (Aire Acondicionado, Lavadoras, Refrigeradoras, Microondas), mientras que Mobile tiene tres, Celulares, Tablets y Accesorios. En este caso en particular, se centrara en Celulares, específicamente en Smartphones (teléfonos celulares inteligentes).

Por lo tanto, Samsung Electronics Peru, opera en la industria de las telecomunicaciones, específicamente en la venta de Smarthpones. Hasta el año pasado, la venta de smartphones se realizaba exclusivamente por los Carriers u Operadores. Es decir, Claro, Movistar, Entel o Bitel. Sin embargo, Samsung, en Octubre del 2017 incursionó en la venta de celulares desbloqueados en retails, supermercados y tiendas especializadas.

La telefonía móvil existe en Perú desde el año 1994, según Osiptel. Los smartphones, sin embargo existen recién desde el 2009, Samsung lanzo su marca de celulares inteligentes ese mismo año, Samsung Galaxy y empezó a venderlos en Perú desde el 2010.

En el mercado de la telefonía móvil, se identifican 2 elementos: la línea móvil (que se tangibiliza en el SIM chip), la cual solo la venden los operadores ya mencionados y el equipo celular. Las líneas puedes ser pre- o post-pago y actualmente existen 2 tipos de celulares, los teléfonos móviles convencionales y los teléfonos móviles inteligentes. Samsung Galaxy, se dedica exclusivamente a la venta de celulares inteligentes. 
El mercado de las telecomunicaciones está regulado por el Organismo Supervisor de Inversión Privada de Telecomunicaciones (OSIPTEL), ente independiente adscrito a la Presidencia del Consejo de Ministros.

OSIPTEL tiene como función principal supervisar y regular el mercado de servicios públicos de telecomunicaciones y velar por los derechos del usuario.

La cantidad de smaprtphones que ingresaron al Perú se han casi triplicado en los últimos cuatro años. Se estima que solo este 2018, se importen 10 millones de celulares. Lo cual elevaría la penetración promedio, a 4 de cada 10 peruanos. (Diario Gestión, 2018)

Sin embargo, el mercado de celulares está retrasado en comparación al resto de la región. Por ejemplo, Brasil tuvo en 2017 una venta de 51 millones de unidades de smartphones, Colombia 11.8 millones, Argentina 10.7 millones y Chile 7.5 millones.

\subsection{Descripción de la empresa en cuanto a los accionistas, estructura organizacional, unidades de negocios, marcas y mezcla de productos}

Samsung Electronics Peru es una sociedad anónima cerrada, lo cual significa que puede tener un máximo de 20 accionistas.

La empresa se estableció en Febrero de 1996 y actualmente se dedica a la Venta Mayorista de Otros Enseres Domésticos, según el CIIU 51395 y a la Venta Mayorista de Otros Productos según el CIIU 51906. La empresa se ubica en Av. Rivera Navarrete 501, San Isidro Lima.

Cuenta con una estructura organizacional tipo lineo-funcional, de acuerdo a las unidades de negocio. Como se mencionó anteriormente, Samsung Perú cuenta con dos unidades de negocio Mobile y Consumer Electronics.

El área de Consumer Electronics se divide en TV's y Línea Blanca. Cada una de estas 3 unidades de negocio (Mobile, TV y Digital Appliences) tiene una estructura funcional, de 4 áreas principales:

- Ventas

- Logística 
- Marketing

- Producto

Adicionalmente, existe una 3era unidad de negocio, Online Business Group, la cual sirve como un apoyo a las otras 2 unidades de negocio. Esta 3era unidad de negocio se dedica a todas las actividades digitales de la compañía. Como la publicidad online, el desarrollo de páginas web, manejo de redes sociales, creación de contenido online...etc.

Existen además 2 áreas de apoyo hacia la gerencia general, el área de finanzas o CFO y el área de administración general.

Figura 1.1

Organigrama Samsung Perú

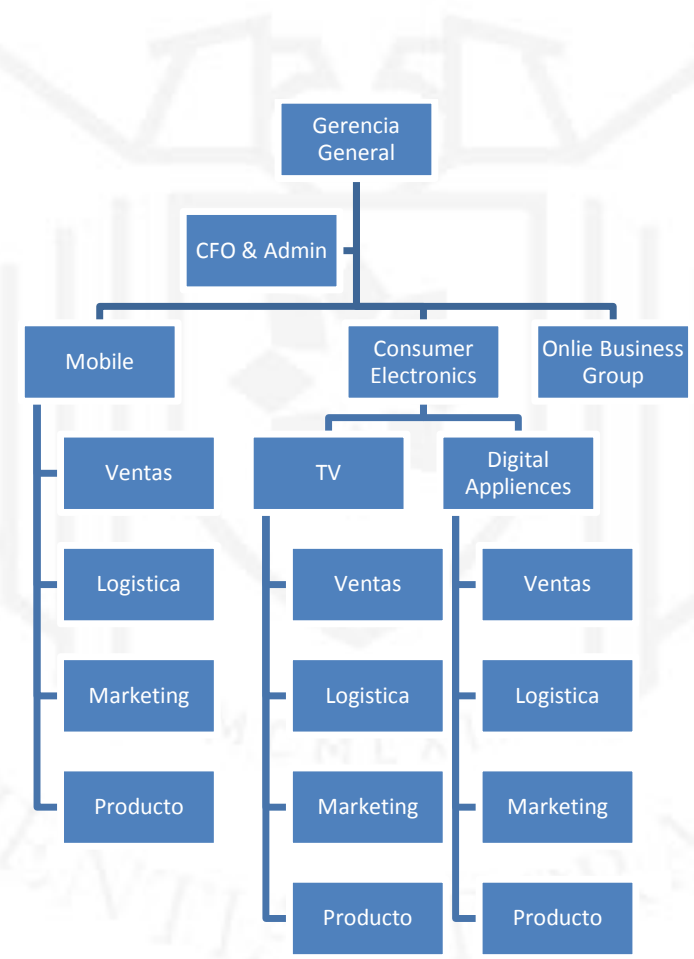

Fuente: Samsung (2018).

Elaboración propia 


\subsubsection{Marcas y mezcla de productos}

Samsung tiene una serie de marcas registradas a nivel mundial. Las podemos catalogar según su unidad de negocio.

Mobile:

- Samsung Galaxy (Celulares, Tablets, Wearables)

Figura 1.1

Logo Samsung Galaxy

\section{SAMSUNG \\ Galaxy}

Fuente: Samsung (2018).

- Samsung Gear (Accesorios)

Figura 1.2

Logo Samsung Gear

\section{SNMSUNG

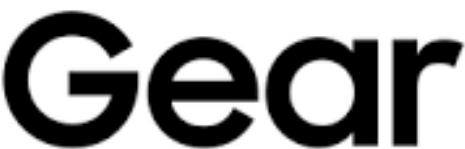

Fuente: Samsung (2018).

TV's:

- Samsung QLED (Televisores y Monitores Premium)

Figura 1.3

Logo Samsung QLED TV 


\section{SAMSUNG}

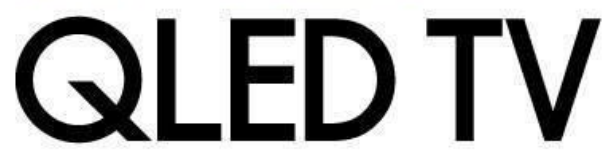

Fuente: Samsung (2018).

DA:

- Samsung Black Edition (Refrigeradoras, Lavadoras, A/C's y Microondas Premium)

Figura 1.4

Logo Samsung Black Edition

\section{SnMsung
BLACKEDITION}

Fuente: Samsung (2018).

La mezcla de Productos de Mobile incluye las 3 categorías mencionadas Celulares, Accesorios y Tablets.

Samsung Cuenta con 4 gamas de celulares:

- Samsung Note

- Samsung S

- Samsung A

- Samsung J

También cuenta con 3 gamas de Tablets

- Galaxy Tab S

- Galaxy Tab A

- Galaxy Tab E

En cuanto a la Categoría de Accesorios se separan en 
- Wearables (Smartwatch, Realidad Virtual, Cámara 360)

- Audio (Audífonos y parlantes)

- Covers (carcasas para celulares y tablets)

- Power (cargadores)

\subsection{Descripción del mercado y sus segmentos}

Considerando los tres últimos años, 2015-2017, observamos que el crecimiento en la tenencia de Smartphone en hogares ha sido de tipo exponencial a nivel Perú. Así tenemos que este tipo de celulares han crecido a nivel nacional $148 \%$ en estos últimos tres años, según nuestra encuesta anual realizada a nivel nacional en 4251 hogares. (CPI, 2017)

Se describe un alto crecimiento a nivel nacional, donde los sectores Ay B presentaron un alza del 61\%, el C 140\% y el DE 253\%, en los últimos 3 años.

Figura 1.5

Evolución de la tenencia de Smartphone

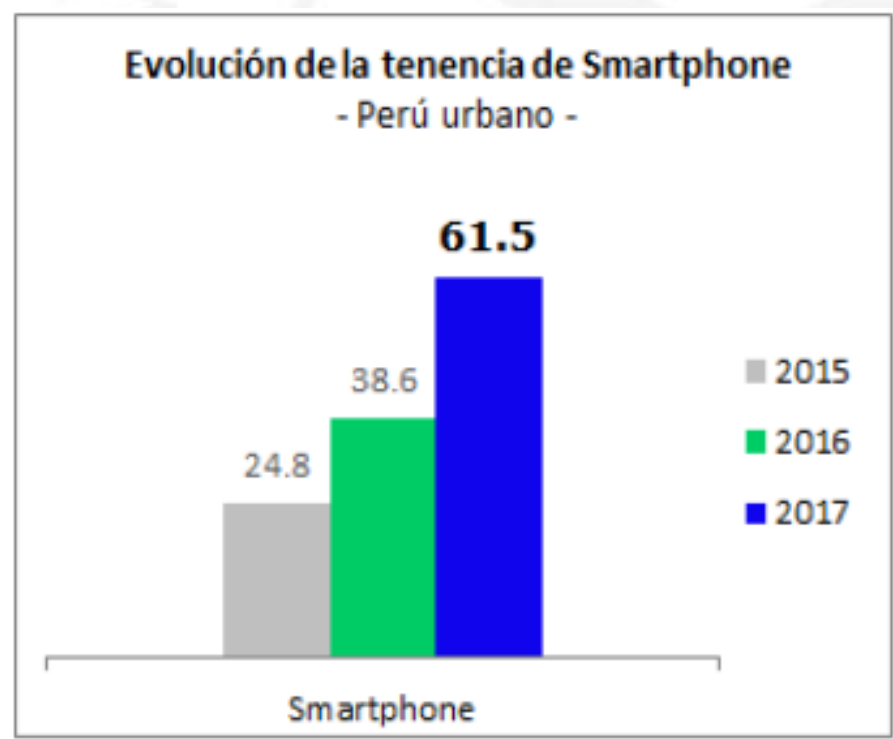

Fuente: CPI (2017). 
Figura 1.6

Evolución de la tenencia de Smartphone por NSE

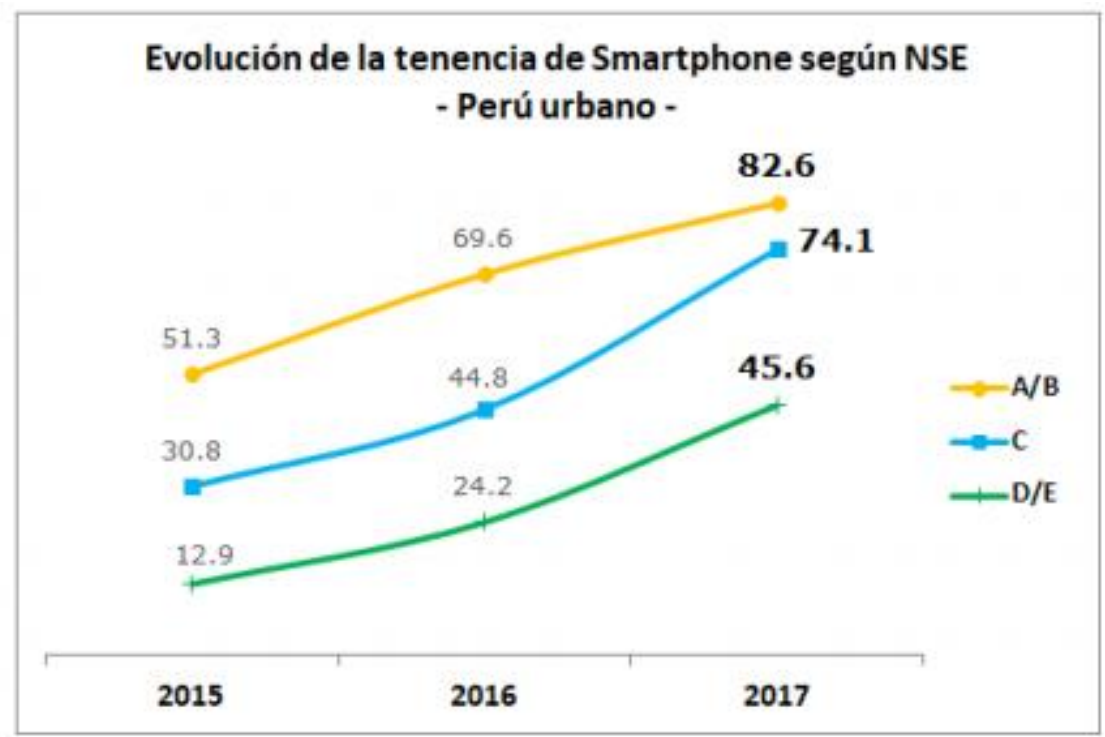

Fuente: CPI (2017).

El aumento de la tenencia de Smartphones se debe principalmente, al interés de los consumidores de contar con internet en sus celulares. El incremento en Lima en los sectores DE fue de 427\% del 2015 al 2017, debido a la entrada de smartphones de bajo costo. En el interior del país el crecimiento fue de $216 \%$.

El impacto de este crecimiento, está afectando a otra categoría del segmento, la telefonía móvil, la cual ha presentado una caída de $15 \%$ en los hogares de los peruanos. El mismo efecto se está presentando en la tenencia de cable, computadoras, Tablets y DVD's. El hecho de que los celulares cuenten con aplicaciones como Netflix o Spotify, genera estos cambios. 
Figura 1.7

Evolución de la tenencia de Telefonía Fija, Celular y Smartphone

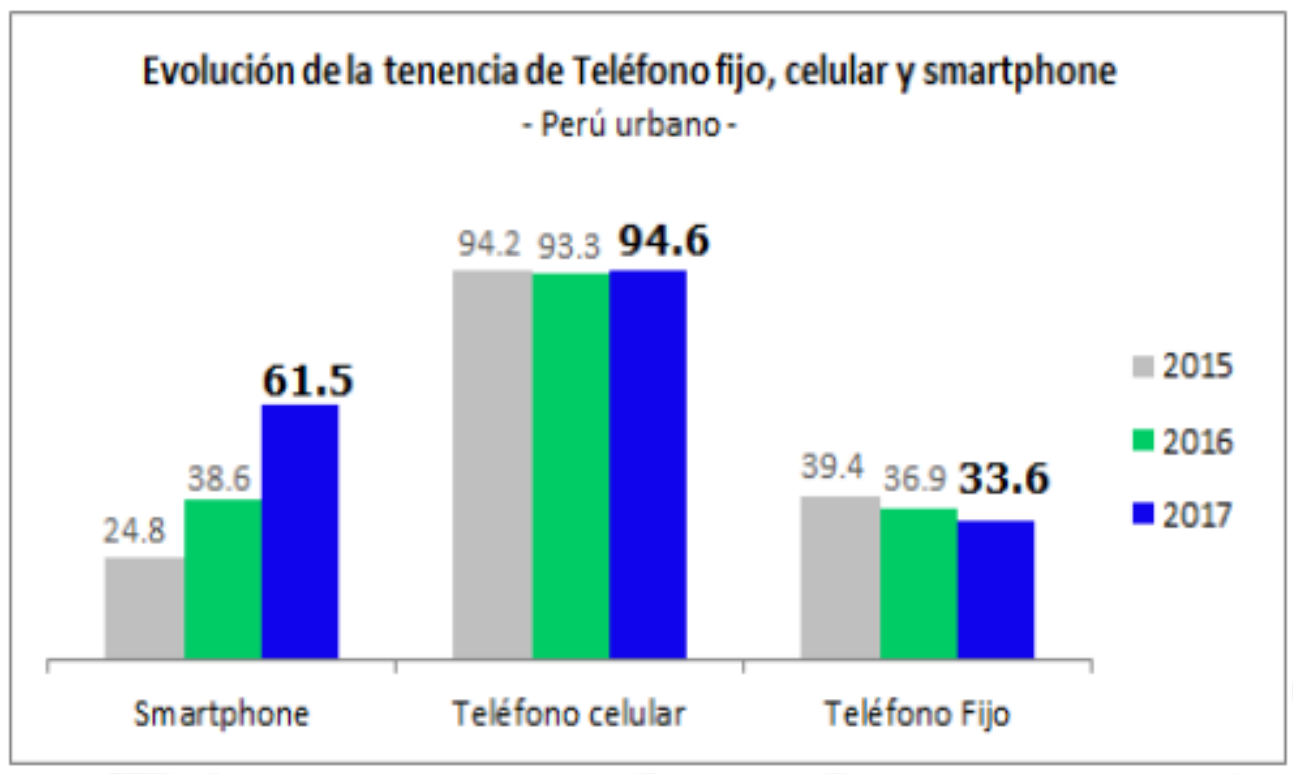

Fuente: CPI (2017).

El mercado de los Smartphones se puede dividir en cuatro:

1. Segmento de Entrada:

Los Smartphones que están destinados al segmento de entrada, tienen un valor máximo de S/.999, cuentan con cámaras digitales cada vez con mejor tecnología pero sin muchas aplicaciones extras, cuentan con procesadores de tecnología intermedia y una batería sobresaliente, debido al bajo rendimiento del celular. Es decir, la capacidad de almacenamiento de la batería no es mayor que los celulares de gamas más altas, pero debido a que el celular no necesita tanta potencia, consumen menos batería.

Están orientados al uso de redes sociales, requerimientos mínimos de fotografía y video, no cuentan con resistencia al agua, carga rápida o cargador tipo-C

2. Segmento Medio

Los Smartphones de la gama media, tienen un costo entre S/.1000 y S/.1800, cuentan con una cámara digital de mejor rendimiento que la gama anterior, un buen procesador que permite usarlo para juegos con requerimientos bajos y para navegar por la web. La definición de pantalla de estos celulares ya tiene un 
mínimo de 1080p, es decir HD. Es este segmento, se ha desarrollado una mejor cámara frontal para los selfies. Los celulares de este segmento están diseñados para, uso fuerte de redes sociales y web, fotografía casual y selfies, uso de aplicaciones de música. Algunos presentan certificaciones IP contra agua y polvo, y capacidades altas de almacenamiento.

3. Segmento Medio-Alto

Los celulares de gama media-alta cuentan básicamente con lo mismo que un celular de gama media, pero con mejores especificaciones técnicas. Se podría decir que incluso ya bordean el segmento Premium, pero no cuentan con todas las características propias del mismo. El procesador es de un excelente rendimiento, y gran capacidad de batería. La mezcla de estas 2 características alarga la vida de la batería, ya que el procesador optimiza el uso requerido de batería por el celular. La cámara ya se puede usar para fotografía amateur, doble cámara frontal, para poder tomar selfies con baja luz, definición 1080p de alta definición El costo de estos celulares va de S/.1900 a S/.2800

4. Segmento Premium

El segmento Premium, es donde las marcas de celulares ofrecen a sus "buques insignia" o flagship. Estos celulares cuentan con todas las características técnicas ofrecidas en los otros segmentos, pero con la tecnología más alta.

Procesador preparado para realizar múltiples tareas, cámaras capaces de tomar fotografías de alta calidad, incluso en baja luz, con modo manual y profesional. Definición 4k de las pantallas, almacenamiento mínimo de $64 \mathrm{gb}$, certificaciones contra agua y polvo, asistencia de inteligencia artificial para mejorar el rendimiento de la cámara, la batería y el procesador. Son los celulares que marcan las tendencias en el mercado por los siguientes 8 a 12 meses.

El precio es mayor a los $\mathrm{S} / .2600$.

En la Tabla 1.1 Smartphones por segmento de Samsung se puede observar los diferentes Smartphones que Samsung tiene para cada segmento de mercado. 


\section{Tabla 1.1}

Smartphones por segmento de Samsung

\begin{tabular}{|c|c|c|c|c|c|c|c|c|c|}
\hline Segmento & \begin{tabular}{|l|} 
Samsung \\
\end{tabular} & Imagen & Costo & Cámara & Procesador & Memoria & Pantalla & Bateria & Otros \\
\hline Entrada & Galaxy J6 + & & S/. 899 & \begin{tabular}{|l|} 
Doble cámara \\
posterior $13.0 \mathrm{MP}+5.0$ \\
Mp Cámara Frontal \\
$8.0 \mathrm{MP}$
\end{tabular} & $\begin{array}{l}1.4 \mathrm{GHz} \text { Quad- } \\
\text { Core }\end{array}$ & $\begin{array}{l}\text { RAM: 3GB } \\
\text { Almacenamiento } \\
\text { Interno: 32GB }\end{array}$ & $\begin{array}{l}1489 \times 720 \\
(\mathrm{HD}+)\end{array}$ & $3300 \mathrm{mAh}$ & $\begin{array}{l}\text { Lector de huellas dactilares, } \\
\text { pantalla infinity, memoria } \\
\text { externa }\end{array}$ \\
\hline \multirow{2}{*}{ Medio } & Galaxy J8 & & S/. 1,199 & \begin{tabular}{|l|} 
Doble cámara \\
posterior $16.0 \mathrm{MP}+5.0$ \\
Mp Cámara Frontal \\
$16.0 \mathrm{MP}$
\end{tabular} & $\begin{array}{l}1.8 \mathrm{GHz} \text { Octa- } \\
\text { Core }\end{array}$ & $\begin{array}{l}\text { RAM: 3GB } \\
\text { Almacenamiento } \\
\text { Interno: 32GB }\end{array}$ & $\begin{array}{l}1489 \times 720 \\
(\mathrm{HD}+)\end{array}$ & $3500 \mathrm{mAh}$ & $\begin{array}{l}\text { Pantalla SAMOLED, Lector } \\
\text { de Huellas digitales, memoria } \\
\text { externa }\end{array}$ \\
\hline & Galaxy A6+ & & S/. 1,299 & \begin{tabular}{|l|} 
Doble cámara \\
posterior $16.0 \mathrm{MP}+5.0$ \\
Mp Cámara Frontal \\
$24.0 \mathrm{MP}$
\end{tabular} & $\begin{array}{l}1.8 \mathrm{GHz} \text { Octa- } \\
\text { Core }\end{array}$ & $\begin{array}{l}\text { RAM: 3GB } \\
\text { Almacenamiento } \\
\text { Interno: 32GB }\end{array}$ & $\begin{array}{l}2220 \times 1080 \\
(\mathrm{FHD}+)\end{array}$ & $3500 \mathrm{mAh}$ & $\begin{array}{l}\text { Pantalla Infinita, Flash Frontal, } \\
\text { Enfoque Dinámico, Parlantes } \\
\text { Dolby, }\end{array}$ \\
\hline Medio-Alto & Galaxy A7 & & S/. 2,799 & \begin{tabular}{|l|} 
Triple cámara \\
posterior $24.0 \mathrm{MP}+5.0$ \\
MP + 8.0MP Cámara \\
Frontal 24.0 MP
\end{tabular} & $\begin{array}{l}2.2 \mathrm{GHz} \text { Octa- } \\
\text { Core }\end{array}$ & $\begin{array}{l}\text { RAM: 4GB } \\
\text { Almacenamiento } \\
\text { Interno: 64GB }\end{array}$ & $\begin{array}{l}2220 \times 1080 \\
(\mathrm{FHD}+)\end{array}$ & $3300 \mathrm{mAh}$ & $\begin{array}{l}\text { IP68, Pantalla Infinity, Flash } \\
\text { Frontal, Parlantes Dolby }\end{array}$ \\
\hline \multirow{2}{*}{ Premium } & Galaxy S9+ & & S/. 3,699 & $\begin{array}{l}\text { Doble cámara } \\
\text { posterior 12.0MP+ } \\
12.0 \text { Mp Cámara } \\
\text { Frontal } 8.0 \mathrm{MP}\end{array}$ & $\mid \begin{array}{l}2.8 \mathrm{GHz}+1.7 \\
\text { GHz Octa-Core }\end{array}$ & $\begin{array}{l}\text { RAM: 6GB } \\
\text { Almacenamiento } \\
\text { Interno: 64GB }\end{array}$ & $\begin{array}{l}2960 \times 1440 \\
(4 \mathrm{~K})\end{array}$ & $3500 \mathrm{mAh}$ & $\begin{array}{l}\text { Apertura dual, IP68, AR } \\
\text { Emoji, SuperSlow Motion, } \\
\text { Parlantes Dolby }\end{array}$ \\
\hline & Galaxy Note9 & 8 & S/. 3,999 & $\begin{array}{l}\text { Doble cámara } \\
\text { posterior 12.0MP+ } \\
\text { 12.0 Mp Cámara } \\
\text { Frontal 8.0 MP }\end{array}$ & $\begin{array}{l}2.8 \mathrm{GHz}+1.7 \\
\text { GHz Octa-Core }\end{array}$ & $\begin{array}{l}\text { RAM: 6GB } \\
\text { Almacenamiento } \\
\text { Interno: 128GB }\end{array}$ & $\begin{array}{l}2960 \times 1440 \\
(4 \mathrm{~K})\end{array}$ & $4000 \mathrm{mAh}$ & $\begin{array}{l}\text { S-Pen, Rendimiento Gamer, } \\
\text { Cámara reinmaginada, } \\
\text { parlantes dolby }\end{array}$ \\
\hline
\end{tabular}

Fuente: Samsung (2018).

Elaboración Propia 


\subsection{Identificación, descripción y participación de mercado de competidores directos}

En la tabla 1.2 Participación de mercado según exportaciones a nivel mundial, se puede observar las marcas líderes a nivel mundial comparando el crecimiento de las marcas comparando el 3er cuarto (julio, agosto, septiembre), de las exportaciones totales de Smartphones.

Tabla 1.2

Participación de mercado según exportaciones a nivel mundial

\begin{tabular}{|l|r|r|}
\hline Cargamentos Globales de Smartphones (\% de Share) & 2017 - Q3 & 2018 - Q3 \\
\hline Samsung & 21 & 19 \\
\hline Huawei & 10 & 13 \\
\hline Apple & 12 & 12 \\
\hline Xiomi & 7 & 9 \\
\hline Oppo & 8 & 9 \\
\hline Vivo & 7 & 8 \\
\hline Lenovo & 4 & 3 \\
\hline LG & 3 & 3 \\
\hline HMD & 1 & 1 \\
\hline Tecno & 1 & 1 \\
\hline Otros & 26 & 22 \\
\hline
\end{tabular}

Fuente: Counterpoint (2018).

Como podemos observar, Samsung se mantiene como líder, sin embargo ha tenido una caída en su participación de $2 \%$, mientras que Huawei, quien el año pasado se encontraba en 3er puesto, ha subido al 2 do lugar con un crecimiento del 3\%. Mientras que Apple mantiene su Share de 12\%, ha caído al 3er lugar. Ni Xiaomi, Oppo, Vivo, Lenovo cuentan con operaciones oficiales en Perú. LG era el competidor directo hasta el año pasado, antes de que Huawei tuviere el crecimiento que viene presentando estos años. Si bien Apple, figura en 3er lugar a nivel mundial, los IPhone, solo compiten en el sector Premium, mientras los equipos van quedando obsoletos, entran en una competencia indirecta con los otros segmentos del mercado.

Mientras Huawei y LG si cuentan con modelos destinados a todos los segmentos.

\section{Huawei}


Huawei Technologies Co. LTD, es una empresa multinacional de origen chino, especializada en alta tecnología, en investigación y desarrollo, producción electrónica y marketing de equipamiento de comunicaciones, así como de redes personalizadas para la industria de telecomunicaciones. Huawei se fundó en 1987 y actualmente cuenta con presencia en más de 100 países. Sus productos se caracterizan por ser de un buen rendimiento a bajo precio.

Figura 1.8

Logo Huawei

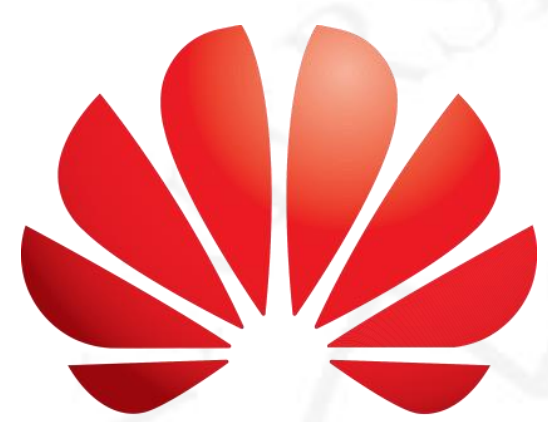

\section{HUAWEI}

Fuente: Huawei (2018).

Huawei en Perú opera con su división B2C de móviles, ofrece Smarpthones, Tablets. Laptops y accesorios. Por otro lado, en Perú, antes de operar como una empresa dedicada a la venta de electrónica de consumo, vendía redes personalizadas para empresas. Recientemente han entrado al mercado de celulares desbloqueados, lo cual representa una amenaza para Samsung.

Huawei cuenta con la serie P Smart, la serie Y, la serie 10 (en sus versiones lite, mate y pro) y la serie P20 (también en versión lite, mate y pro).

Los celulares se catalogan en los siguientes segmentos:

- Segmento de Entrada : Huawei P Smart, Huawei Y5, Huawei Y6

- Segmento Medio: Huawei Y7, Huawei Mate 10 Lite

- Segmento Medio-Alto: Huawei Mate 10 Mate, Huawei 10 Pro Huawei P20Lite

- Segmento Premium: Huawei P20 Mate, Huawei P20 Pro. 
El competidor directo del Galaxy S9|S9+ en el momento del lanzamiento era el Mate 10 y el 10 Pro, sin embargo en el mes de Junio se lanzó la serie P20. El P20 Mate es la competencia directa del S9 y el P20 Pro del Galaxy S9+.

\section{LG}

LG Electronics, es la competencia directa de Samsung a nivel mundial, no solo en el rubro de telefonía celular, ya que también se dedica a la venta de línea blanca y línea marrón al igual que Samsung.

Al igual que Samsung, es una empresa coreana con presencia mundial y es reconocida mundialmente por la calidad de sus productos. Hasta hace 2 años, LG era la competencia directa de Samsung en todos los segmentos del mercado, antes de la entrada de Huawei. Sin embargo, los bajos costos de Huawei afectaron directamente a LG, ya que Samsung sique manteniendo su posicionamiento de producto de calidad y por el valor percibido de la marca los consumidores aún siguen comprando Galaxy. En el caso de LG, la diferencia del valor percibido con los productos de Huawei si justifican un menor precio.

Figura 1.9

Logo LG

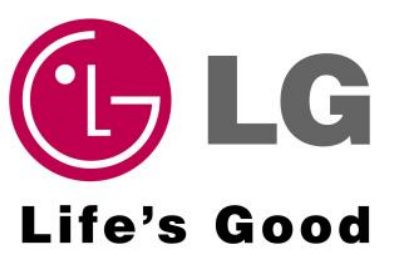

Fuente: LG (2018).

Los celulares se catalogan en los siguientes segmentos:

- Segmento de Entrada : Serie K $(8,9,10)$

- Segmento Medio: Serie K (11)

- Segmento Medio-Alto: Q Stylus

- Segmento Premium: G7

\section{Apple}


Apple es una empresa estadounidense, que se dedica al diseño producción de equipos electrónicos, software y servicios en línea. La empresa se fundó en 1976 en California.

Según Interbrand, Apple es actualmente la marca más valiosa del mundo, con un valor calculado en \$184,154 millones. Su producto estrella actualmente es el IPhone. El primer Iphone se lanzó en 2007 y desde el primer diseño se caracterizó por ser un celular Premium de alto costo pero de excelente rendimiento.

Figura 1.10

Logo Apple

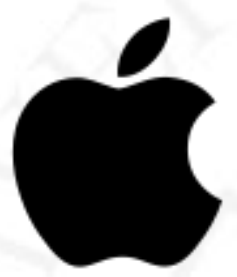

Fuente: Apple (2018).

Apple solo compite en el segmento Premium del mercado, sin embargo, con el paso del tiempo los celulares tienden a bajar de precio, con la llegada de los nuevos modelos y los consumidores que no pueden comprar el último modelo optan por comprar las versiones anteriores.

Actualmente Apple se encuentra en su 13ra generación de celulares. Desde la 8ma generación (iPhone 6 y 6plus) Apple lanza 2 modelos de iPhone. Para poder competir con los Galaxy S y Galaxy Note. Al igual que Huawei, Apple lanzo 3 celulares, el iPhone Xs, Xs Max y XR, los cuales compiten con el S9, S9+ y Note9 respectivamente.

Los consumidores de iPhone son muy leales a la marca, por el valor agregado que entrega la marca, además que los iPhones operan con un sistema operativo propio, el IOs. Lo cual fideliza al cliente, ya que cambiar de sistema operativo es el principal motivo para no cambiar de marcas para los usuarios de iPhone. 


\section{CAPÍTULO II: DIAGNÓSTICO DEL MARKETING ESTRATÉGICO DE LA EMPRESA}

\subsection{Descripción y análisis de la estrategia genérica}

De acuerdo con Michael Porter (2008, pág. 51), existen tres estrategias genéricas de gran eficacia que ayudarán a lograr un mejor desempeño que la competencia en una determinada industria. Estas son: liderazgo global en costos, diferenciación y enfoque o concentración.

Samsung se basa en la estrategia de diferenciación, que se describe como aquella característica o características únicas que ofrece una marca en una industria específica. Esto se logra gracias a la calidad de los componentes del producto, el diseño de la marca, la tecnología implementada y el servicio post venta al cliente. Todo esto con el fin de poder fomentar la lealtad y la fidelización del cliente hacia la marca.

En las diferentes gamas en las que compite Samsung, se diferencia de sus competidores por los atributos de mayor calidad que tienen los celulares frente a su competencia. Los celulares Galaxy están en constante innovación, debido a la naturaleza del mercado, para siempre entregar productos novedosos y de calidad a sus clientes.

\subsection{Descripción y análisis de la(s) ventaja(s) competitiva(s)}

La ventaja competitiva es la capacidad de una empresa para desempeñarse de una o más maneras que sus competidores no pueden igualarse a ella (Kotler y Keller, 2016, pág. 798). Para crear relaciones duraderas y rentables con los clientes, se necesita cada día entregar más valor y satisfacer más necesidades a comparación de la competencia. (Kotler y Armstrong, 2016, pág. 544)

Por eso Samsung, tiene toda un área de Investigación y Desarrollo en Corea, que se dedica a estudiar las tendencias comerciales y las necesidades del cliente. Además Samsung cuenta con la tecnología de punta disponible en el continente asiático y está en constante desarrollo de nuevas tecnologías para satisfacer las necesidades de sus clientes. Prueba de ello es el celular Galaxy Note9 que se lanzó en Septiembre de este año, siendo el Smartphone con la batería más potente del mercado, uno procesador de 6gb de RAM y una memoria expandible hasta 1Terabyte. 
Según Ferrell y Hartline (2016), las empresas desarrollan ventajas competitivas en base de una de las siguientes tres estrategias: excelencia operativa, liderazgo del producto e intimidad con el cliente.

Samsung Galaxy, se caracteriza por el liderazgo de sus productos. No solo sus celulares Note o Galaxy S (celulares Premium) se destacan, en todas sus gamas siempre tienen novedades tecnológicas. Los celulares $\mathbf{J}$ (segmento de entrada) ya cuentan con diseño Premium e incluso dos cámaras posteriores.

\subsection{Descripción y análisis de la(s) estrategia(s) de marketing corporativo que aplica}

De acuerdo a la Matriz Ansoff, creada por Igor Ansoff en 1957, existen cuatro estrategias principales para asegurar el crecimiento de una empresa. Las cuatro estrategias se detallan en la siguiente figura:

Tabla 2.1

Matriz de Ansoff

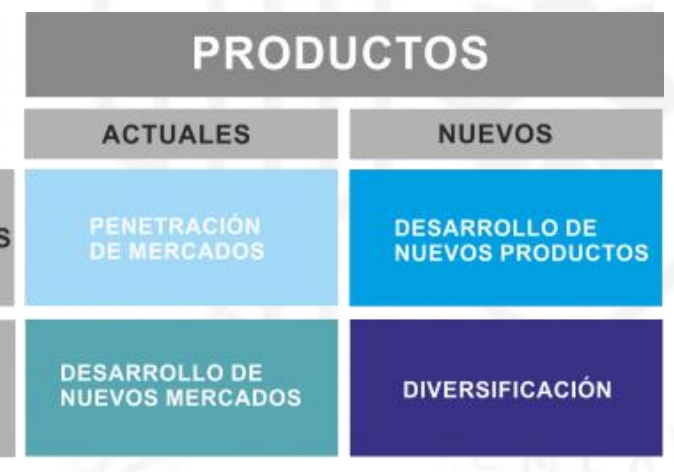

Fuente: Ansoff (1957).

En el caso de Samsung, se estaría aplicando una estrategia de crecimiento en mercados actuales, mediante el desarrollo de producto. Ya que el Samsung Galaxy S9|S9+, es una versión nueva de la gama Galaxy S, el sucesor del Galaxy S8. Se le agregan nuevas y mejores características, se restable la funcionalidad y se aplican nuevas tecnologías, todo esto con el fin de añadir más valor al producto. 


\subsection{Descripción y análisis de la(s) estrategia(s) competitiva(s) de marketing que aplica}

Según Kotler y Keller (2016, pág. 337), existen cuatro estrategias competitivas que una empresa puede ejercer: líder, retador, seguidor o especialista en nichos.

El líder de mercado se caracteriza por poseer la participación más grande en una determinada industria y/o categoría. Este posee mayor cobertura de distribución, cambios de precios, intensidad de promociones y lanzamiento de nuevos productos. Para conservar el liderazgo, las empresas deben aplicar las siguientes sub estrategias: expandir la demanda de mercado, proteger su participación de mercado actual e incrementar su participación de mercado. (Kotler y Keller, 2016)

Samsung, es una marca líder en el mercado tanto nacional como a nivel mundial, con la línea Galaxy. Como sub-estrategias para mantener el liderazgo, se buscó expandir la demanda de mercado actual, proteger su participación e incrementar la participación.

- Expandir la demanda de mercado: La estrategia de comunicación del Galaxy S9|S9+, se centró en dar a conocer el nuevo color exclusivo de la marca, el morado Lilac Purple, dirigido a las mujeres. Los esfuerzos de publicidad se centraron en comunicar al segmento de Mujeres de 25 a 55 años, empresarias, trabajadoras, las funcionalidades del celular y el celular en su versión morada.

- Proteger la participación de mercado actual: El mercado de los Smartphones se puede dividir en dos tipos de usuarios, los que usan Android y los que usan IOS, por cuestiones conductuales, los usuarios que usan uno de los dos sistemas operativos no son propensos a cambiar al otro. Entonces, Samsung no tiene que preocuparse mucho por que Apple le pueda quitar clientes, tiene que centrarse en que los otros Smartphones de Android no destaquen. El Galaxy S9, se lanzó como el celular más potente del mercado, por lo que sus competidores directos no pudieron igualar la calidad del mismo.

- Incrementar la participación de mercado: Con los esfuerzos de publicidad mencionados, para captar mayor público femenino, se buscó incrementar la participación de mercado en la gama alta. La cual actualmente es el punto fuerte de IPhone. Se buscó, captar la atención de las mujeres independientes, con la capacidad económica de comprar el celular. 


\subsection{Descripción del(los) grupo(s) objetivo que atiende}

Samsung Perú, tiene una mezcla de productos que atiende a diferentes grupos objetivos según sus necesidades. Cuenta con la línea de móviles, línea blanca (electrodomésticos) y línea marrón (tv’s, audio y video)

Sin embargo, el Galaxy S9|S9+, pensando en un grupo objetivo más específico. Aunque la comunicación estaba basada principalmente en el público femenino, estaba dirigido también a hombres. Esta táctica se utilizó para reforzar lo que el público masculino ya sabía del celular y para dar a conocer el nuevo color del celular, el morado.

Para dividir los mercados en grupos homogéneos, se agrupa a la población de acuerdo con las cuatro principales variables de segmentación: geográfica, demográfica, conductual y psicográfica.

Tabla 2.2

Segmentación del Galaxy S9|S9+

\begin{tabular}{|c|c|c|}
\hline VARIABLE & SUB- VARIABLES & DETALLE \\
\hline \multirow[t]{3}{*}{ 1. GEOGRÁFICA } & Región & Principales Ciudades de Lima \\
\hline & Provincia & $\begin{array}{l}\text { Lima, Piura, Arequipa, Cusco, } \text { La } \\
\text { Libertad, Lambayeque, Ica }\end{array}$ \\
\hline & Ciudades & $\begin{array}{l}\text { Lima, Cusco, Arequipa, Trujillo, La } \\
\text { Libertad, Piura,Ica }\end{array}$ \\
\hline \multirow[t]{3}{*}{ 2. DEMOGRÁFICA } & Edad & De $25-55$ años \\
\hline & Género & Hombre y mujer \\
\hline & Clase social & Pertenecientes a los NSE A, B y C \\
\hline 3. CONDUCTUAL & Beneficios esperados & $\begin{array}{l}\text { Calidad, tecnología innovadora, cámara } \\
\text { digital de más de } 8 \text { MP. }\end{array}$ \\
\hline 4. PSICOGRAFICA & $\begin{array}{l}\text { Personalidad y estilo de } \\
\text { vida }\end{array}$ & $\begin{array}{l}\text { Personas activas, empresarios, } \\
\text { trabajadores o independientes, que buscan } \\
\text { siempre lo último en tecnología y esta } \\
\text { actualizados con la misma. }\end{array}$ \\
\hline
\end{tabular}

Fuente: Elaboración Propia 


\subsection{Descripción del posicionamiento de la empresa o marca(s)}

Según Kotler y Amstrong (2007), las estrategias de posicionamiento de una marca pueden ser por lo siguiente:

- Atributo: la estrategia se enfoca en características específicas de la marca.

- Beneficio: se resalta un beneficio que proporciona en particular la marca.

- Calidad o precio: en esta relación, la marca ofrece la mayor cantidad de beneficios a un precio en relación a ello.

- Competencia: compara las ventajas y atributos de la marca con las marcas rivales.

- Uso o aplicación: la estrategia hace énfasis en cómo, cuándo, dónde o con que finalidad utiliza determinado producto.

- Categoría de producto: se enfoca en posicionar a la marca como líder en su categoría.

\subsection{Descripción de la creación del brand equity de su(s) marca(s)}

El valor de la marca, refleja las emociones o las asociaciones que puede tener el cliente hacia ella. Es un valor agregado, este se puede representar económicamente, estratégicamente y aprovecharse por la empresa de manera administrativa.

Según la página Interbrand (2017), la marca Samsung esta valorizada en \$56,249 millones, ubicada en el 6to puesto del ranking. La página define a Samsung, como "una empresa dedicada a hacer el mundo un lugar mejor, mediante diversos negocios. La principal compañía es Samsung Electronics, la cual lidera a nivel global el mercado, en manufactura electrónica de alta tecnología y medios digitales".

Según Keller (2013, pág. 79), para construir el valor de una marca se necesitan 4 pasos:

1. Identidad de la marca: Asegurar que los consumidores identifiquen y relacionen la marca con un beneficio o necesidad particular.

2. Significado de la marca: Establecer el significado de la marca en la mente de los consumidores.

3. Respuesta de la marca: Provocar respuestas adecuadas hacia la marca por parte de los consumidores. 
4. Relación de la marca: Convertir las respuestas hacia la marca en relaciones duraderas con los consumidores.

Para poder entender mejor el alto valor de la marca, se utilizara como referencia la pirámide de resonancia de Keller, que se observa en la siguiente figura:

\section{Figura 2.1}

Pirámide de valor de la marca Samsung
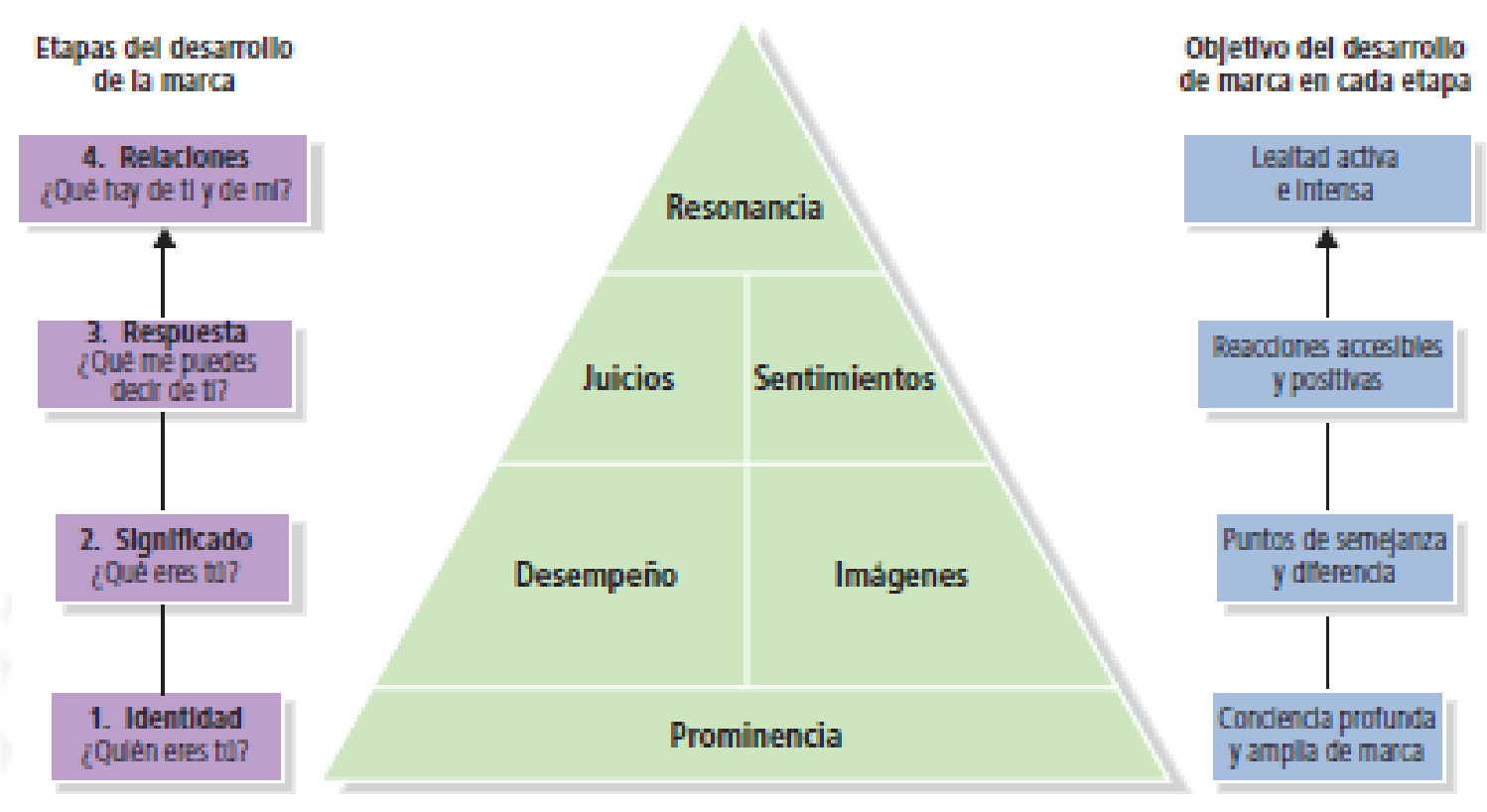

Fuente: Arquitectura de la marca (Keller, 2008)

a) Prominencia: este nivel mide la conciencia que tienen los consumidores de una respectiva marca, como la frecuencia que las personas recuerdan a esta y la capacidad del cliente para reconocerla en diferentes situaciones (Keller, 2008, pág. 61). Samsung es una marca reconocida y líder globalmente, con más de 50 años en el mercado, presente en diferentes rubros.

b) Desempeño: describe si el producto satisface adecuadamente las necesidades funcionales que esperan los clientes (Keller, 2008, pág. 64). En los diferentes mercados y segmentos en los que Samsung tiene presencia, se caracteriza por tener productos de excelente calidad. Por ejemplo, el Galaxy Note9 recientemente lanzado, es el Smartphone más potente del mercado. Los celulares Galaxy, están constantemente en el ranking de los mejores celulares.

c) Imaginería: se refiere a los aspectos intangibles de una marca y las asociaciones que puede formar un cliente respecto a ella como los perfiles de uso, situaciones de compra y uso, 
personalidad, valores, historias y experiencias (Keller, 2008). En el caso de Samsung, la marca se caracteriza por ser una marca joven, innovadora y de calidad.

d) Juicios: este cuadrante hace referencia a las opiniones y evaluaciones personales que los clientes tienen hacia una marca de acuerdo a la calidad, credibilidad, consideración y superioridad (Keller, 2008, pág. 64). Como se ha mencionado anteriormente, el rendimiento de los productos Samsung son de primera calidad, cuentan con diferentes certificaciones según el rubro del producto, que garantizan el buen funcionamiento y desempeño del mismo.

e) Sentimientos: son aquellas respuestas y reacciones emocionales que genera la marca hacia el cliente (Keller, 2008, pág. 64). Samsung genera sentimientos de confianza y de seguridad, ya que constantemente ha probado tener productos de buen desempeño. Además cuenta con el respaldo de la marca Samsung a nivel mundial.

f) Resonancia: es el último nivel que describe la intensidad de la relación que existe entre una marca y los consumidores. En ella se detalla el grado de sintonía que sienten los clientes respecto a la marca ocasionando lealtad (Keller, 2008, pág. 72). Samsung comercializa productos tecnológicos, de especialidad. Por lo tanto antes de comprar uno de estos productos, los consumidores suelen investigar y comparar los beneficios de la competencia. La calidad y el buen desempeño de los productos Samsung, sumado al valor de la marca suelen generar un vínculo con sus consumidores, los cuales por lo general, quedan fidelizados. 


\section{CAPÍTULO III: DESCRIPCIÓN DEL CASO PROBLEMA}

La campaña de lanzamiento del Galaxy S9|S9+, se inició la segunda mitad de marzo, generando expectativa sobre el lanzamiento en Perú, mediante esfuerzos publicitarios. Anterior al lanzamiento se creó una página de pre-venta, para que los clientes interesados puedan ser los primeros en adquirir el equipo.

La campaña se realiza durante todo abril y junio. Se estableció un objetivo mayor al del modelo anterior, el Galaxy S8|S8+. La campaña para el Galaxy S9|S9+ se centró en su cámara reimaginada y en el nuevo color morado, Lilac Purple, enfocado en el público femenino. A diferencia de los modelos Galaxy S anteriores, el S9 y el S9+ tiene una diferencia significativa entre ambos modelos: la doble cámara del S9+.

Si bien la campaña obtuvo buenos resultados, hubo un problema con las ventas de ambos modelos, el S9+ se vendió más de lo esperado y el S9 se vendió menos de lo que se había proyectado. Además los modelos en morado, superaron las expectativas, el negro cumplió con su objetivo y el gris no llego a cumplir la cuota fijada.

A continuación, en el capítulo III: DESCRIPCION DEL CASO PROBLEMA, se expondrá las técnicas de marketing operativo que se realizaron durante la campaña, para poder entender la campaña realizada. En el capítulo IV: ANÁLISIS Y DISCUSIÓN DE RESULTADOS, se analizarán los resultados obtenidos y las acciones correctivas que se podrían haber tomado.

\subsection{MARKETING OPERATIVO}

\subsubsection{Producto}

El Samsung Galaxy S9|S9+, es un Smarthphone de sistema operativo Android fabricado por Samsung Mobile. Es parte de la serie S, la gama alta de celulares de Samsung. A diferencia de los celulares Note, los celulares de la gama $\mathrm{S}$ son de gama alta pero son más accesibles para el público. El lanzamiento global del celular fue en 16 de marzo y llego a Perú en abril.

El Galaxy S9|S9+ es el sucesor del Galaxy S8|S8+, lanzados en el año 2018. Uno de los principales atractivos del Galaxy S8, fue la "pantalla infinity", es decir una pantalla sin bordes ni marcos en el celular. El Galaxy S9 visualmente es muy parecido a su antecesor, presenta unos cuantos cambios, como la ubicación de la cámara y el lector de huella digital. 
La principal característica a mejorar, en la cual se enfocó Samsung para este nuevo celular, fue la cámara. La cámara reinmaginada, como se le denomino y fue parte del slogan del celular, presento considerables mejoras. Introduciendo al mercado los videos "super-slow motion", que graba a 960 fps (frames per second), frente a la competencia que tiene slow motion de 720 fps (un video a velocidad normal tiene $60 \mathrm{fps}$ ). Los Frames per second, se puede traducir como la cantidad de imágenes que se reproducen en un segundo.

Otra novedad fue la doble abertura del obturador de la cámara, que admite una apertura focal de F1.5 hasta F2.4, lo cual permite al usuario tomar fotos con una calidad de superior en cualquier condición de luz (ya sea de día o de noche). También se presentó el Emoji de realidad aumentada, el cual se creaba con la cámara del S9. Es tan simple como abrir la cámara, elegir el modo AR Emoji y escanear la cara del usuario que desea tener su propio Emoji animado. A continuación se presentan las características principales del celular:

Tabla 3.1

Características del Galaxy S9|S9+

\begin{tabular}{|l|l|l|}
\cline { 2 - 3 } \multicolumn{1}{c|}{} & S9 & S9+ \\
\hline Procesador & Octa-Core 2.8 GHz & Octa-Core 2.8 GHz \\
\hline Pantalla & $\begin{array}{l}\text { Dual Edge Super AMOLED (2960 x } \\
1440 \text { Quad HD+) }\end{array}$ & $\begin{array}{l}\text { Dual Edge Super AMOLED (2960 x } \\
1440 \text { Quad HD+) }\end{array}$ \\
\hline $\begin{array}{l}\text { Tamaño de } \\
\text { Pantalla }\end{array}$ & $5.8^{\prime \prime}(146.5 \mathrm{~mm})$ & $6.2^{\prime \prime}(158.0 \mathrm{~mm})$ \\
\hline $\begin{array}{l}\text { Cámara } \\
\text { Principal }\end{array}$ & $12 \mathrm{MP}(\mathrm{F} 1.5 / \mathrm{F} 2.4$ Apertura Dual) & $\begin{array}{l}12.0 \mathrm{MP}(\mathrm{F} 1.5 / \mathrm{F} 2.4 \text { Apertura Dual) }+ \\
12.0 \mathrm{MP}(\mathrm{F} 2.4)\end{array}$ \\
\hline Cámara Frontal & $8 \mathrm{MP}(\mathrm{F} 1.7)$ & $8 \mathrm{MP}(\mathrm{F} 1.7)$ \\
\hline $\begin{array}{l}\text { Resolución de } \\
\text { video }\end{array}$ & $\mathrm{UHD} 4 \mathrm{~K}(3840 \times 2160)$ & UHD 4K (3840 x 2160) \\
\hline Memoria Ram & $4 \mathrm{~GB}$ & $6 \mathrm{~GB}$ \\
\hline $\begin{array}{l}\text { Memoria } \\
\text { Interna }\end{array}$ & $64 \mathrm{~GB}+64 \mathrm{~GB}(\mathrm{SD})$ & $64 \mathrm{~GB}+64 \mathrm{~GB}(\mathrm{SD})$ \\
\hline Batería & $3000 \mathrm{mAh}$ & $3500 \mathrm{mAh}$ \\
\hline
\end{tabular}

Fuente: Samsung (2018).

Elaboración propia.

En la versión anterior, el Galaxy S8|S8+, la única diferencia entre ambos modelos era el tamaño de pantalla y de la batería. En este caso estas diferencias se mantienen, el S9+ presenta un $17 \%$ más de batería y una pantalla más grande, que el S9. Sin embargo, el S9+ presenta una doble cámara posterior, mientras que el S9 solo tiene una. Esta doble cámara, permite al S9+ capturar fotos con enfoque dinámico. La gran angula, cuenta con 12MP y la apertura dual, el Galaxy S9 
cuenta además con una cámara teleobjetivo de $12 \mathrm{MP}$ pero solo con una apertura focal de 2.4 y un rango de foto de $45^{\circ}$.

Esta cámara adicional, permite al Galaxy $\mathrm{S} 9+$, tomar fotos con enfoque dinámico. Este modo de foto, detecta la profundidad de los objetos y permite tomar fotos con efecto bokeh (con fondo difuminado), como una cámara profesional. El S9, cuenta con una función de enfoque dinámico, pero se realiza digitalmente, diferencia del $\mathrm{S} 9+$ toma dos fotos y las junta para realizar el efecto deseado. Además el difuminado se puede controlar.

Cuenta además con la certificación IP68, norma internacional de la Comisión Electrónica Internacional (o IEC, por sus siglas en ingles), la cual asegura que el celular tiene el grado de protección contra agua y polvo más alta para un Smartphone. IP68, significa Ingress Protection (protección contra ingresos), el 6 significa que tiene protección fuerte contra polvo, ya que no ingresara polvo al celular en ninguna circunstancia y el 8 significa que cuenta con una protección contra la inmersión completa y continua en agua (hasta 30 minutos a 1 metro de profundidad).

Ambos modelos en el mercado peruano se ofrecieron en 3 colores, Morado (Lilac Purple) Negro (Midnight Black) y Gris (Titanium Gray):

Figura 3.1

Colores del Samsung Galaxy S9|S9+

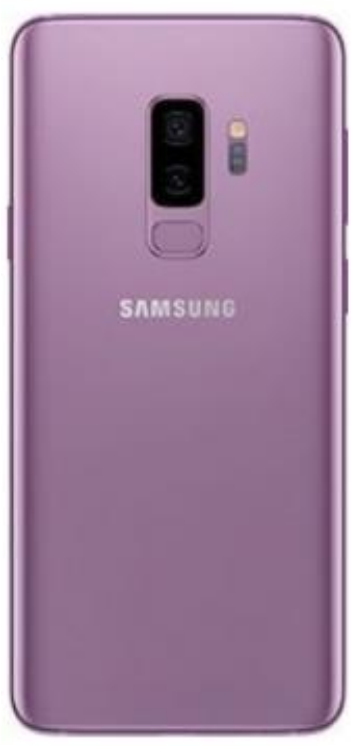

Lilac Purple

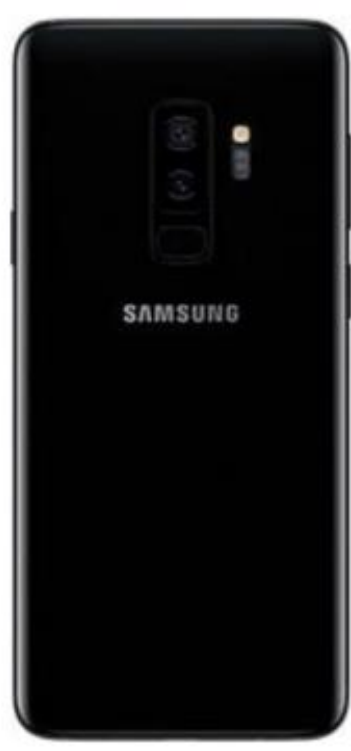

Midnight Black

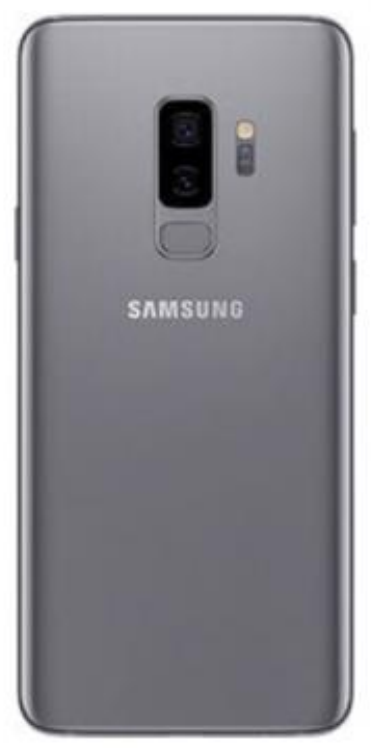

Titanium Gray

Fuente: Samsung (2018). 
Para definir mejor el producto, Kotler y Armstrong (2017) recomiendan utilizar los niveles de producto descritos en la siguiente figura 3.2 Niveles de producto:

Figura 3.2

Niveles de producto

Fuente: Kotler y Amstrong (2017).

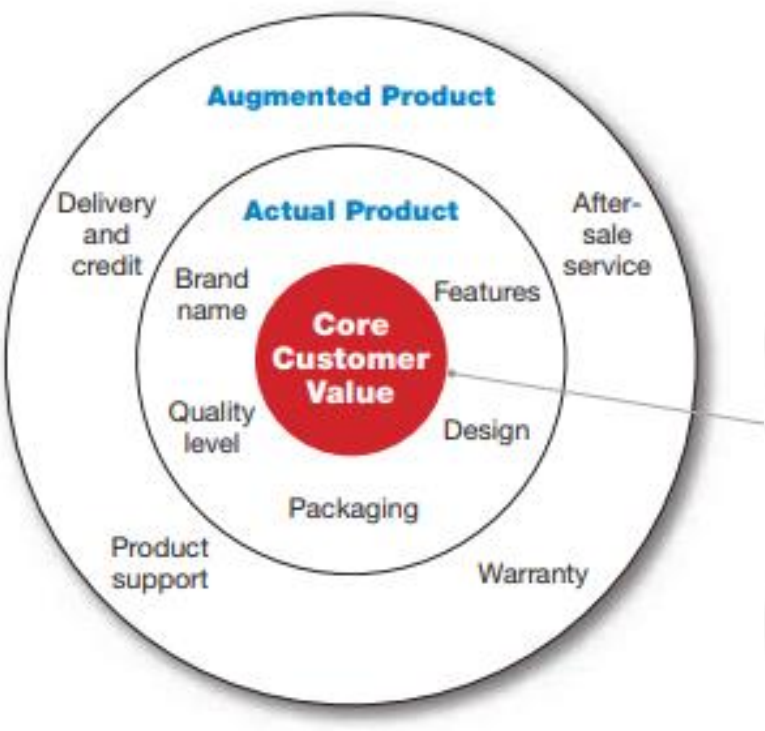

En el caso del Samsung Galaxy S9|S9+, los niveles son descritos de la siguiente manera:

- Valor principal del cliente: lo que realmente está comprando el cliente un celular inteligente para poder comunicarse vía teléfono y poder usar aplicaciones, que le faciliten el día a día.

- Producto actual: el producto sería la marca Samsung Galaxy y todas las características técnicas, de alta gama con las que cuenta el celular. Todo esto entrega un valor adicional al producto, ya que es un producto de alta calidad, lo cual se refleja en su rendimiento, presentación, empaque y diseño.

- Producto aumentado: Al comprar un producto Samsung Galaxy, el cliente adquiere un producto de alto valor y calidad. Además automáticamente, pasa a formar parte de la comunidad Samsung Members. Esta comunidad, se ve reflejada en un App que tiene el 
celular descargada por defecto, donde se puede pedir asistencia en tiempo real, hacer diagnósticos del celular, abrir foros de debate sobre el celular, entre otros. Externo a Samsung members, Samsung cuenta con una línea telefónica para servicio técnico. Si el producto se ha entregado defectuoso, automáticamente se reemplaza y si no se busca una forma de solucionar el problema.

Según el criterio de clasificación de Kotler y Armstrong (2017), los productos se pueden dividir en dos: productos de consumo y productos industriales. Dentro de los productos de consumo existen cuatro tipos: productos de conveniencia, de especialidad, de compra esporádica y no buscados.

El Samsung Galaxy S9|S9+, es considerado un producto de especialidad, debido las siguientes características:

- Compra no muy frecuente, mucho esfuerzo de planeación y comparación de calidad, precio y estilo

- Precios altos

- Distribución selectiva

- Publicidad y venta personal tanto por el fabricante como por los revendedores

\section{Empaque}

Como dice Czinkota y Kotabe (2001) el empaque es inevitable para poder entregar el producto al consumidor final en buenas condiciones. Asimismo, según Stanton, Etzel y Walker (2007) el empaque es un factor necesario para conseguir distribución y clientes.

Según la Amercian Marketing Associaction (A.M.A. 2018), existen tres niveles del empaque:

a) El empaque primario es aquel que contiene el producto principal. En el caso del Galaxy S9|S9+ es el producto como tal, hecho de plástico, con bordes de metal y pantalla de vidrio.

b) El empaque secundario es aquel que contiene uno o más paquetes primarios. En este caso es la caja en la que viene el celular con sus accesorios correspondientes.

c) El empaque terciario es aquel que contiene uno o más empaques secundarios. En este caso, son las cajas con 20 unidades que se envían internacionalmente. 
Figura 3.3

Empaques primarios Galaxy S9|S9+

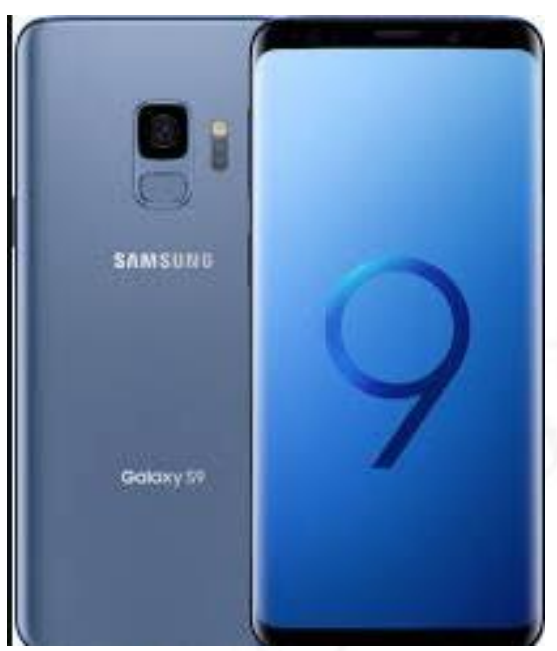

Fuente: Samsung (2018).

Figura 3.4

Empaques secundarios Empaques primarios Galaxy S9|S9+

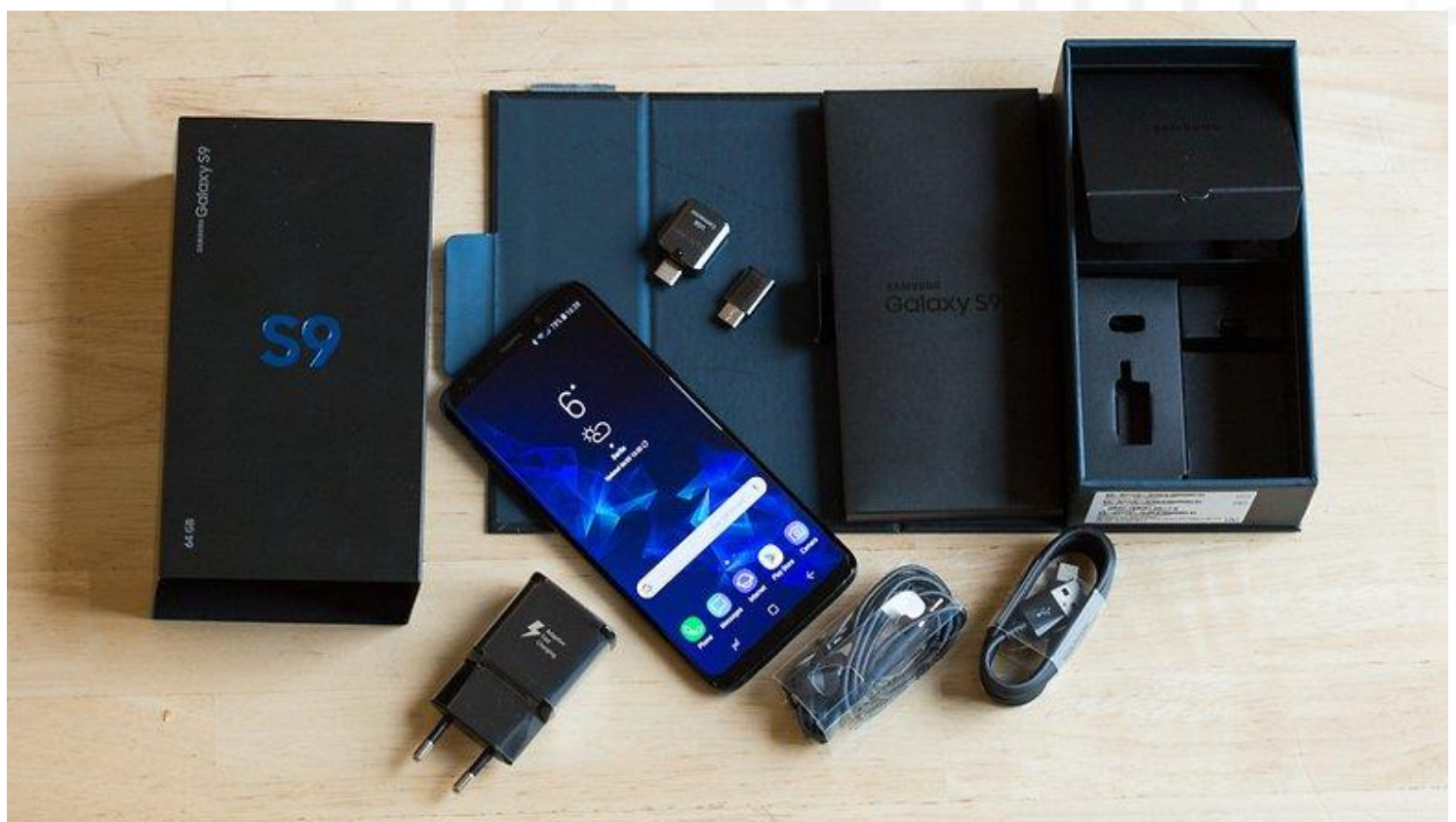

Fuente: Samsung (2018). 
Figura 3.5

Empaques terciario Galaxy S9|S9+

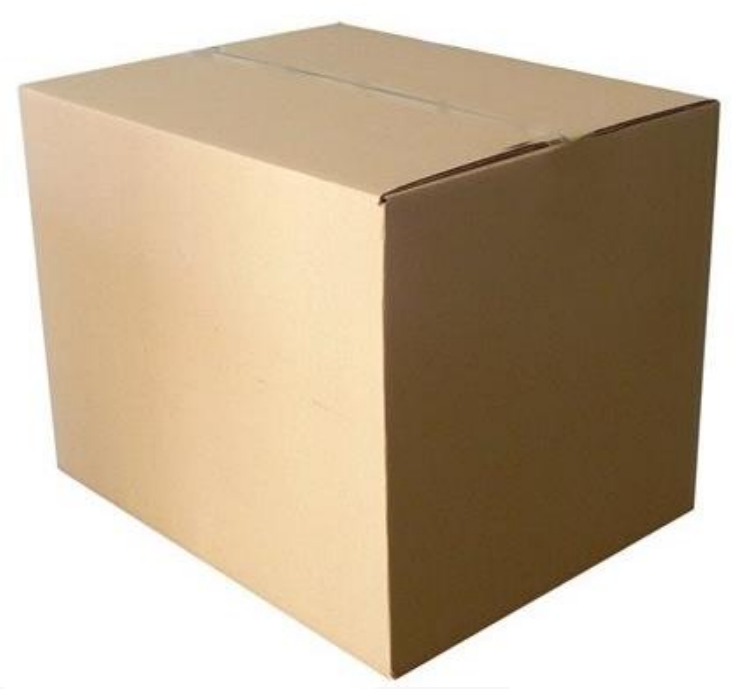

\section{La marca}

El Samsung Galaxy S9|S9+, se comercializa bajo la marca Samsung Galaxy, la cual existe desde 2015 y es la marca designada para la gran mayoría de productos de la línea de "mobile", tales como los celulares y las tablets. Cada producto Galaxy, cuenta con un logo adaptado de la marca Samsung Galaxy y el modelo correspondiente del producto, como se aprecia en las siguientes imágenes:

Figura 3.6

Logo de la Marca

\section{SAMSUNG}

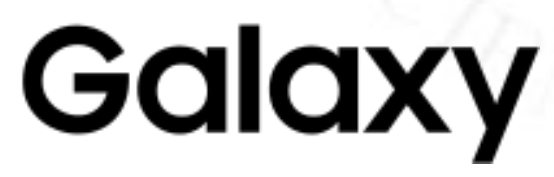

Fuente: Samsung (2018). 
Figura 3.7

Logo del Producto

\section{SIMSUNG}

\section{Galaxy S9}

Fuente: Samsung (2018).

Según el reporte de Abril del 2018 de rendimiento de smarthpones Android, de la página web Antuntu (http://www.antutu.com/en/doc/114647.htm), el Galaxy S9+ y el Galaxy S9, fueron los celulares más potentes en el mes de su lanzamiento.

Figura 3.8

Top 10 Rendimiento de Smartphones Android

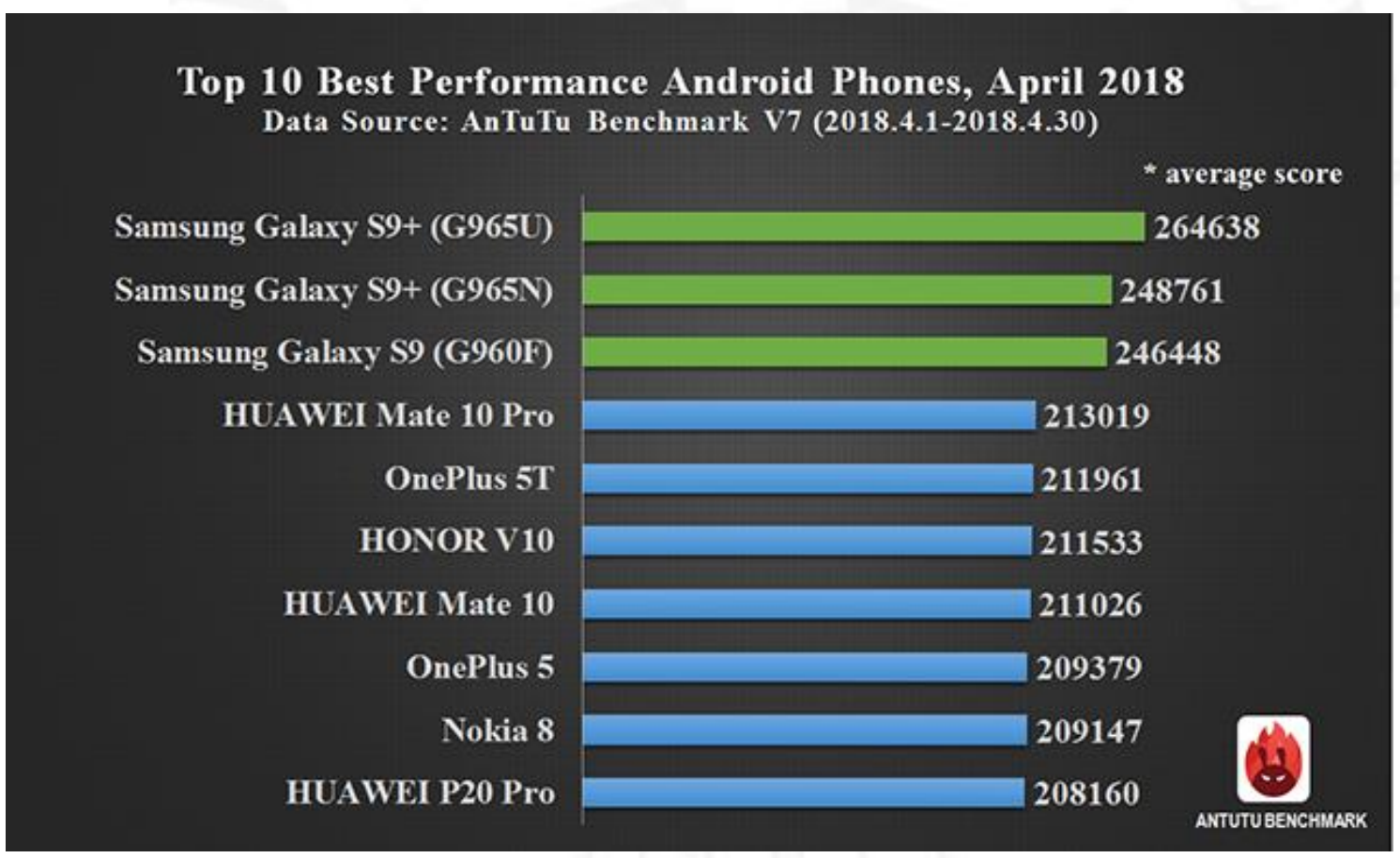

Fuente: Antuntu (2018).

Por otro lado, según IPSOS (2017), Samsung es la 1era de las 6 marcas con mayor recordación dentro de los Smartphoneros peruanos. 


\subsubsection{Precio}

De acuerdo a Kotler y Amstrong (2017), existen tres consideraciones principales para fijar los precios: fijación de precios basada en el valor para el cliente, basada en el costo y basada en la competencia.

En el caso del Samsung Galaxy $\mathrm{S} 9 \mid \mathrm{S} 9+$, se toman en cuenta las tres principales consideraciones.

\section{Fijación de precios basada en el valor para el cliente}

Debido a que finalmente, el consumidor es quien decidirá si el precio de un producto es correcto o no, hay que tener en cuenta el valor percibido del comprador.

Al momento de realizar la compra de un producto, los compradores intercambian dinero a cambio de un producto que les otorgue valor (beneficios y necesidades que satisface el producto). En este caso, el consumidor está eligiendo comprar un celular de alta gama, lo cual se traduce en un alto valor monetario.

Para esto es importante entender, el valor que conceden los consumidores a un producto como este. Los Samsung Galaxy S, están posicionados como un producto Premium, generalmente los Galaxy S y los IPhone son quienes marcan las tendencias de los celulares en esta gama. Sin embargo los Huawei de alta gama ya son un participante a tomar en cuenta.

Es aquí, donde la percepción del valor percibido del cliente, permite cobrar aproximadamente un $16 \%$ por el Galaxy S9+

\section{Fijación de precios basada en el costo}

Se decide establecer los precios a partir de los costos de producción, distribución y venta del producto agregando un porcentaje adicional de utilidades por el esfuerzo realizado por la elaboración del producto. (Kotler y Armstrong, 2017)

En el caso del Galaxy S9|S9+ el precio se fija mediante márgenes. Es decir que sobre el precio de importación se adiciona un sobreprecio, para llegar al precio de venta del producto. 
Los celulares son importados de Corea y sobre el valor FOB se adiciona aproximadamente un $60 \%$.

El S9 tiene un precio FOB aproximado de S/.1, 438 y el S9+ de S/.1, 563

\section{Fijación de precios basada en la competencia}

De acuerdo a Kotler y Armstrong (2017, pág.271), toda empresa debe tomar en cuenta los precios de su competencia, ya que debe asegurar de entregar a sus clientes un valor superior por ese precio. Este tipo de fijación de precios implica basarse en estrategias de costos, precios y ofertas de los competidores del mercado al que se está incursionando.

Los celulares son importados de Corea y sobre el valor FOB se adiciona aproximadamente un $60 \%$. A continuación, se presentará en la siguiente tabla con los precios de la competencia del Galaxy S9 y Galaxy S9+.

Figura 3.9

Precios de la competencia del Galaxy S9

\begin{tabular}{|l|l|l|}
\hline Samsung S9 & IPhone 8 & Huawei P20 \\
\hline S/. & S/. & S/. \\
3,200 & 3,600 & 2,999 \\
\hline
\end{tabular}

Elaboración propia.

Figura 3.10

Precio de la competencia del Galaxy S9+

\begin{tabular}{|l|l|l|}
\hline Samsung S9+ & IPhone $X$ & Huawei P20 Pro \\
\hline S/. & S/. & S/. \\
3,700 & 3,999 & 3,500 \\
\hline
\end{tabular}

Elaboración propia. 


\section{Determinación de precio por canal}

Samsung cuenta con 3 canales de venta Retailers/Supermercados, Carriers u Operadores.

El precio de venta para cada uno es el mismo. Sin embargo los Carriers, pueden fraccionar el costo del celular al consumidor final de acuerdo al plan tarifario con el cual se adquiere el equipo. Mientras más cara la tarifa mensual, menor es el costo de fraccionamiento del equipo. Además se puede elegir entre 12 y 18 meses de contrato. Los carriers ofrecen como servicio adicional, seguros para los equipos.

En promedio, los clientes generan un margen de rentabilidad de 39\% con el Galaxy S9 y un $48 \%$ con el Galaxy S9+.

Tabla 3.2

Precio por canal

\begin{tabular}{|c|c|c|c|c|c|}
\hline & \begin{tabular}{|l|} 
Samsung \\
FOB
\end{tabular} & Rentabilidad & $\begin{array}{l}\text { Intermediario } \\
+60 \%\end{array}$ & Rentabilidad & Cliente \\
\hline S9 & $\begin{array}{l}S / . \\
1,438\end{array}$ & $60 \%$ & $\begin{array}{l}\mathrm{S} / . \\
2,300\end{array}$ & $39 \%$ & \begin{tabular}{|l|}
$S /$. \\
3,200
\end{tabular} \\
\hline S9+ & \begin{tabular}{|l}
$S /$. \\
1,563 \\
\end{tabular} & $60 \%$ & \begin{tabular}{|l}
$S /$. \\
2,500 \\
\end{tabular} & $48 \%$ & \begin{tabular}{|l|}
$S /$. \\
3,700 \\
\end{tabular} \\
\hline
\end{tabular}

Elaboración propia.

\section{Estrategia de fijación de precio de nuevos productos}

Según Stanton, Etzel y Walker (2007), poner un precio inicial relativamente alto para un producto nuevo se le denomina asignación de precios descremados en el mercado. De ordinario, el precio es alto en relación con la escala de precios esperados del mercado meta. Esto es, el precio se pone al más alto nivel posible que los consumidores más interesados pagarán por el nuevo producto.

Dada la naturaleza del producto, el ciclo de vida de los celulares de alta gama, no es mayor a 14 meses. Cuando se lanza un nuevo modelo, se fija un precio elevado, para que sea adquirido por los clientes que realmente buscan el producto y tienen la capacidad de económica de adquirirlo. Por otro lado, los operadores saben que existe una demanda alta por este tipo de teléfonos y como se explicó anteriormente, ofrecen facilidades de financiamiento a los clientes. 
Por otro lado, a inicios de Junio, se estableció una alianza estratégica con Diners Club y BBVA, para llevar a cabo una campaña de financiamiento de productos Galaxy, siendo el S9 el foco de la comunicación. Esta campaña, permite a los usuarios pagar el celular a 12 cuotas sin interés.

Figura 3.11

Financiamiento $\mathrm{S} 9 \mid \mathrm{S} 9+$

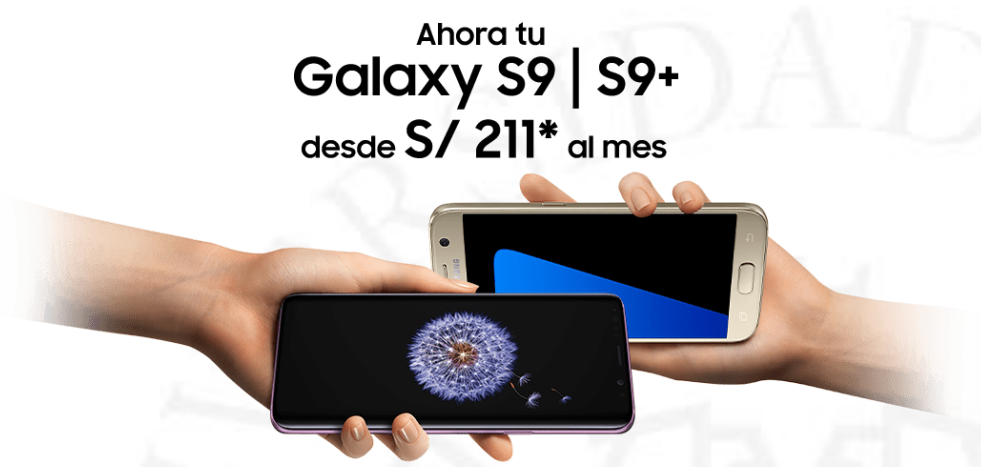

Fuente: Samsung (2018).

\section{Fijación de precios promocional}

Por oportunidad de lanzamiento, los diferentes canales cuentan con promociones exclusivas para sus clientes. Cada KAM de cuenta ofrece un stock máximo de 100 accesorios iguales a la cuenta correspondiente, para que el minorista a su vez lo ofrezca a los 100 primeros compradores. Estos accesorios, se ofrecen a mitad de precio, para que el canal pueda ofrecerlos junto con el celular a los clientes como oferta de lanzamiento.

Con esto se busca aumentar la demanda a corto plazo y generar mayor expectativa entre los consumidores. Además es un diferencial para cada canal de distribución, ya que los precios son iguales entre los diferentes puntos de venta.

\subsubsection{Plaza}

En el caso de Samsung, para la unidad de celulares, el tipo de distribución es canales de marketing indirecto, ya que existen uno más niveles de intermediarios. Con este tipo de distribución, se tiene 
que determinar los tipos de intermediarios que serán los más adecuados para cubrir sus necesidades. (Stanton, Etzel y Walker, 2007)

Sin embargo, existe un canal de venta directa, las tiendas propias.

De acuerdo a Kotler y Armstrong (2017), un nivel de canal es considerado como cada capa de intermediarios de marketing que realizan algún trabajo para acercar el producto al consumidor final. El número de niveles de intermediarios indica la longitud del canal.

Como se mencionó anteriormente, existen tres canales principales de venta de celulares. Los carriers, que adquieren los celulares los homologan con contenido propio de las líneas telefónicas que ofrecen y los venden con plan de pago mensual (post-pago) o como celulares prepago.

El otro canal, donde se venden los celulares desbloqueados y que están homologados para tener cualquier línea, son los Retailers y los Supermercados. En el caso de las tiendas propias, los celulares también se venden desbloqueados y homologados para todas las líneas.

Samsung cuenta con 5 tiendas propias ubicadas en los principales Malls de Lima:

Jockey Plaza, Megaplaza, Plaza Norte, Mall del Sur y Plaza San Miguel.

En las siguientes figuras, se representan los canales de distribución de acuerdo al tipo de intermediario: 
Figura 3.12

Canal de Carriers

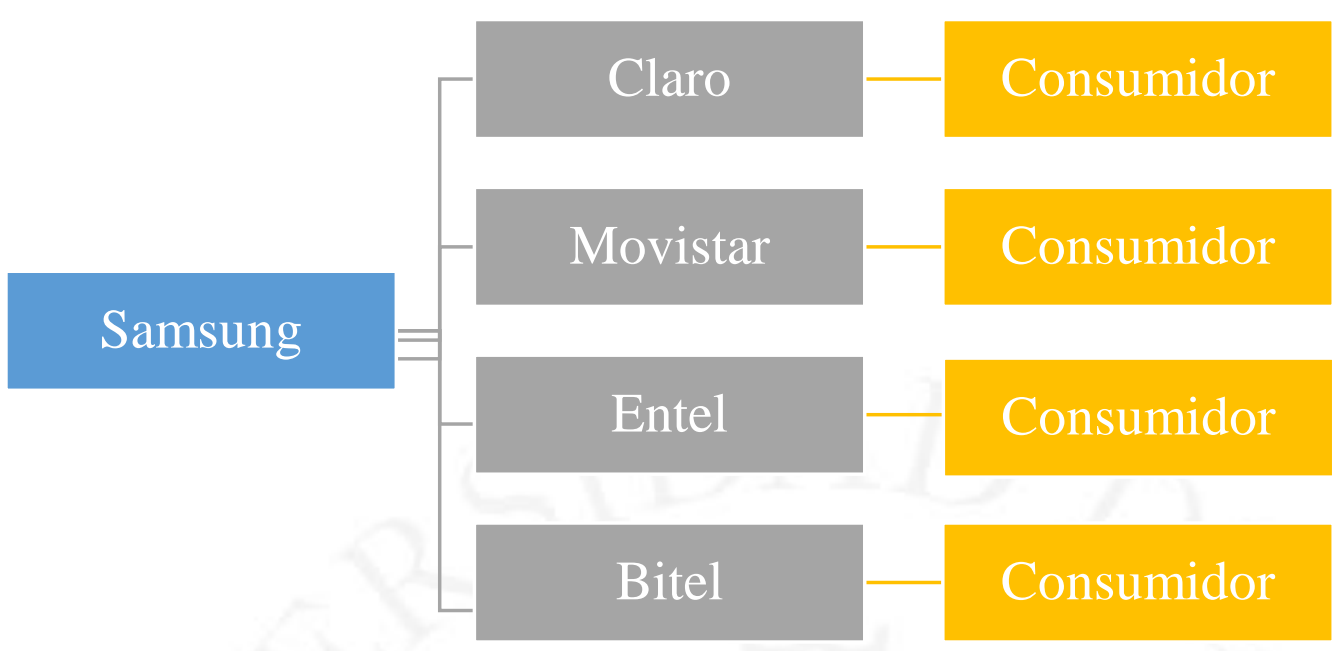

Fuente: Elaboración propia.

\section{Figura 3.13}

\section{Canal de Retailers y Supermercados}

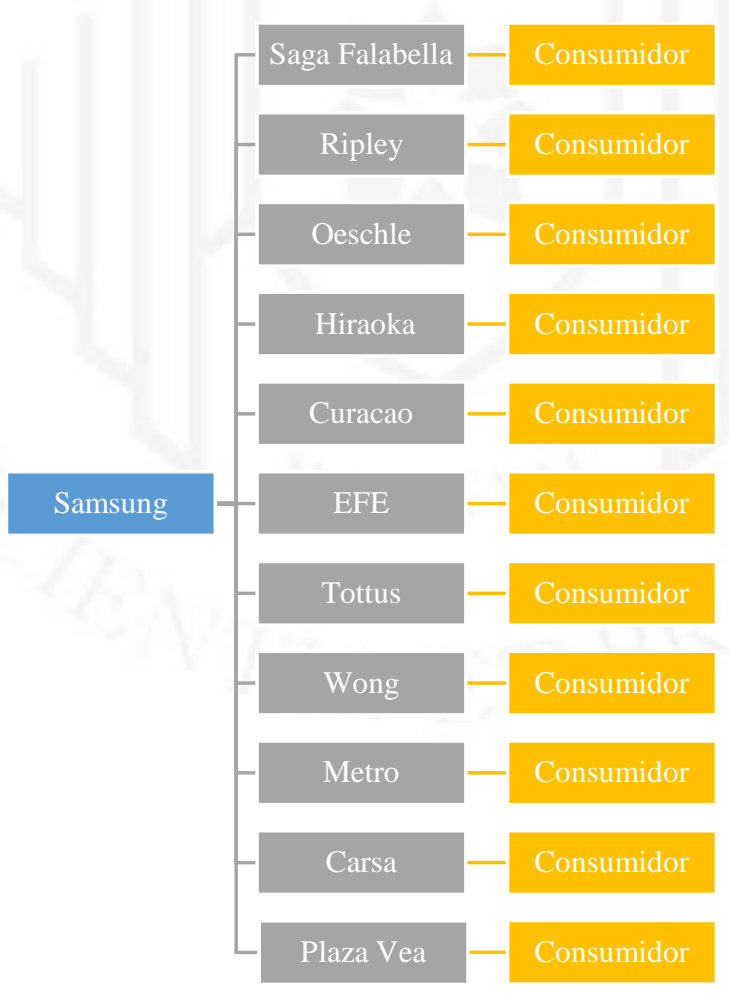

Fuente: Elaboración propia. 
Figura 3.14

Canal Tienda propia

\section{Samsung}

Fuente: Elaboración propia.

\section{Tipo de Distribución del Galaxy S9|S9+}

Según Stanton, Etzel y Walker (2007), la distribución selectiva, el productor vende su producto a través de múltiples mayoristas y detallistas, pero no de todos los que pueda haber, en un mercado en el que un consumidor pueda razonablemente buscarlo.

En el caso del Galaxy S9|S9+, la distribución será selectiva, ya que Samsung Galaxy vende sus productos a través de varios intermediarios, aunque no todos los intermediarios existentes que están dispuestos a distribuir los productos de la compañía. Se espera que con este tipo de distribución se realce la imagen de la marca, se fortalezca el servicio al cliente, se mejore el control de calidad y se mantenga alguna influencia sobre sus precios.

\section{Tabla 3.3}

Participación del negocio por canal

\begin{tabular}{|c|c|c|c|}
\hline Carriers & Retailers Supermercados & Tiendas Propias & TOTAL \\
\hline $60 \%$ & $25 \%$ & $15 \%$ & $100 \%$ \\
\hline
\end{tabular}

Fuente: Elaboración propia. 
Como se puede observar, la distribución sigue concentrada en los carriers, debido al poco tiempo que tiene el mercado de celulares desbloqueados en el Perú. El carrier que domina la participación del canal es Movistar, seguido por Entel, Claro y finalmente Bitel.

Sin embargo, el canal de celulares desbloqueados (retailers/supermercados y tiendas propias), en su totalidad ya supero el total de ventas de Claro. El competidor más fuerte dentro de este segmento, es Saga seguido de Ripley y las tiendas propias.

\subsubsection{Promoción}

Segú Stanton, Etzel y Walker (2007, pág. 505), desde la perspectiva del marketing, la promoción sirve para lograr los objetivos de una organización. En ella, se usan diversas herramientas para tres funciones promocionales indispensables: informar, persuadir y recordar al público objetivo.

Se definen las tres funciones de la siguiente manera:

- Informar: Mas allá de solo tener conciencia de un producto o marca, los consumidores deben entender los beneficios que proporciona, como funciona y como obtenerlo.

- Persuadir: En el mercado actual, dado la cantidad de oferta, los consumidores disponen de muchas alternativas para satisfacer sus necesidades. Por eso la publicidad persuasiva es esencial, para lograr que el cliente opte por la marca que se desea.

- Recordar: Se debe recordar a los consumidores sobre la disponibilidad y el potencial de satisfacer una necesidad que tenga un producto. Con esto, se busca crear un lugar en la mente del consumidor. 


\section{La mezcla de la promoción}

Kotler y Armstrong (2017, pág. 366) mencionan que la mezcla de promoción consiste en la combinación específica de cinco elementos: publicidad, promoción de ventas, ventas personales, relaciones públicas y marketing directo y digital. Estas herramientas, se utilizan para poder comunicar valor al cliente en forma persuasiva y poder establecer relaciones con ellos.

Tomando en cuenta lo expuesto anteriormente, se presenta a continuación los diferentes esfuerzos de marketing que se realizaron, usando las herramientas mencionadas, se utilizaron tanto medios ATL (Above the Line), como medios BTL (Below the Line). El target principal de la comunicación fue principalmente hombres y mujeres entre los 25 y 55 años. Trabajadores u independientes, de NSE A, B y C, con un estilo de vida activo, enfocado a los negocios y/o a la tecnología.

○ TV: Spots televisivos de 30 segundos, menciones en programas televisivos alineados al target como programas médicos y programas con alto nivel de rating como son los noticieros diarios en horario nocturno. Las menciones contaran con pases a tanda y banners digitales.

Ejemplo: Mujeres sin Filtro, N Noticias, TEC, la Banda del Chino, Futbol en America

Figura 3.15

Mención Televisiva Galaxy S9

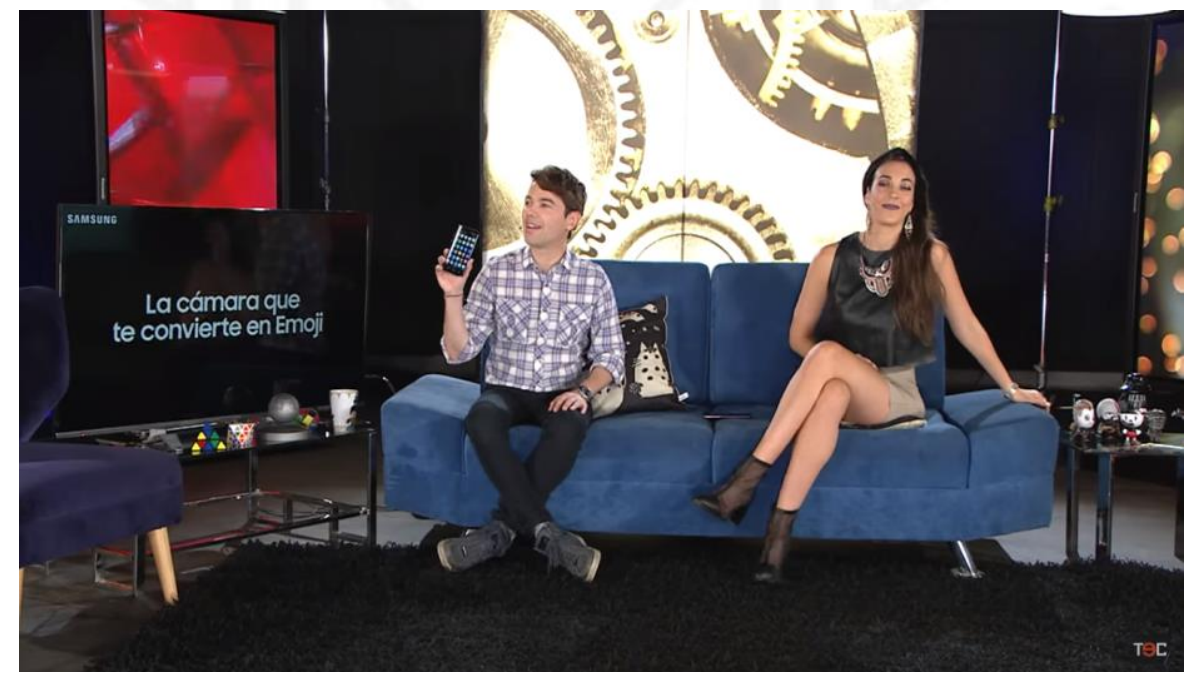

Fuente: America Televisión (2018).

- Radio: Anuncios radiales en espacios publicitarios y menciones en programas alineados al target. Ejemplo: Studio 92 (Mal elemento), RPP (noticias) 
- Material impreso: Incluyendo revistas y periódicos, se contarán con espacio publicitario para poder informar sobre el producto Ejemplo: Campaña con Publímetro, paginas completas en El Comercio.

- Vía pública: Se contó con presencia masiva en diferentes centros comerciales del país, además de vallas estáticas y digitales. En Lima, malls como Jockey Plaza, Megaplaza, Plaza Norte, Mall del Sur, Plaza San Miguel, Plaza Lima Sur, Centro Cívico. Además de mallas en Cusco, Arequipa y los Aeropuertos de Chiclayo y Trujillo.

Figura 3.16

OOH Megaplaza

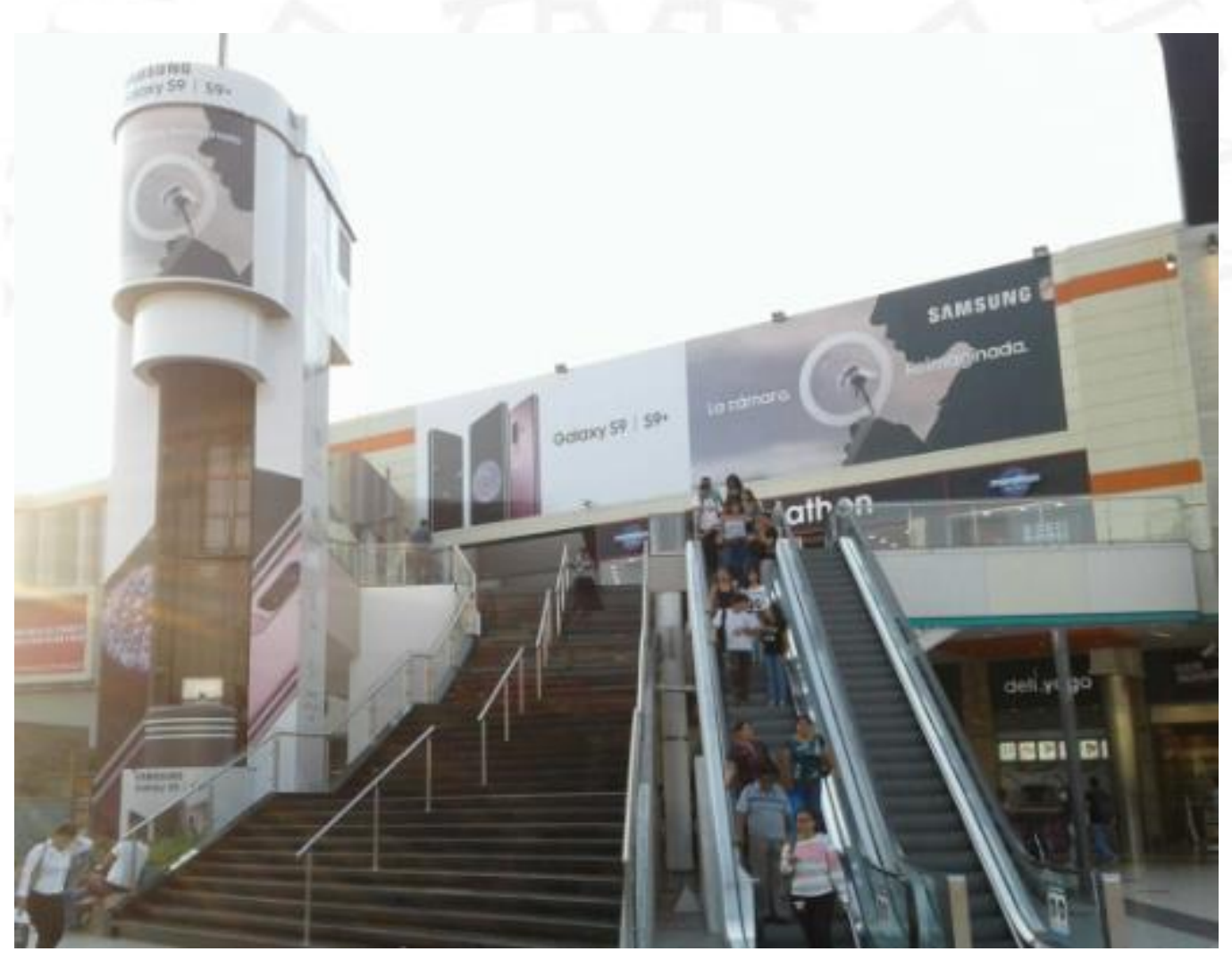

Elaboración propia. 
Figura 3.17

OOH Vía Pública

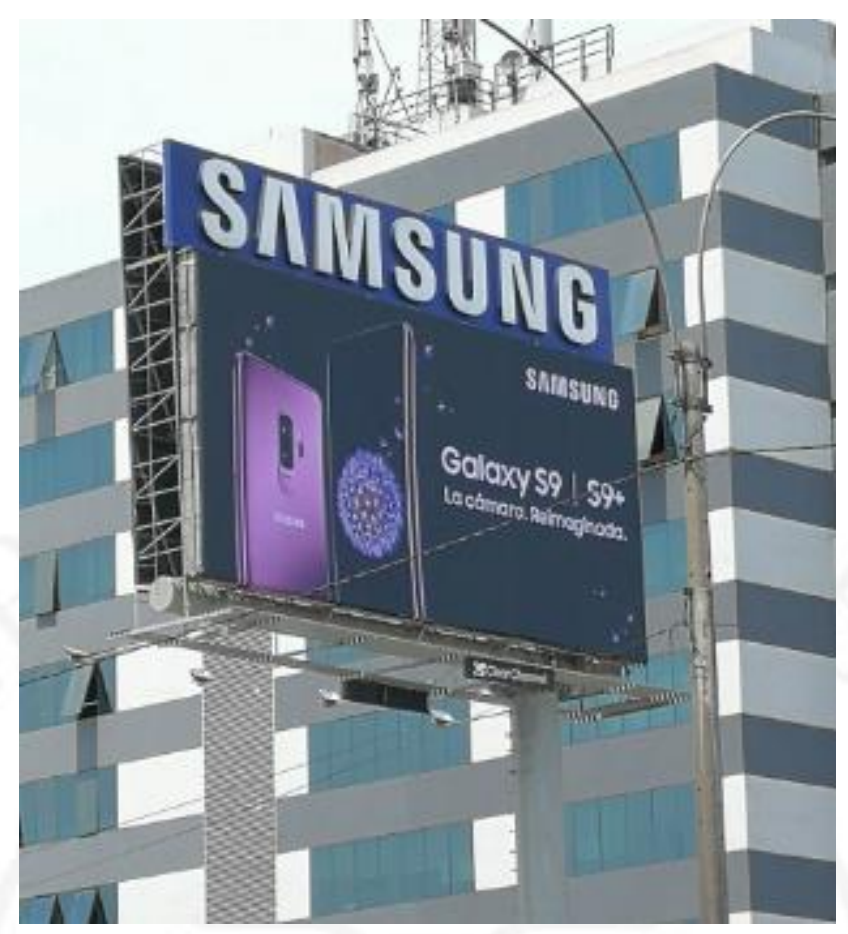

Elaboración propia.

○ Medios Digitales: Pauta tanto en redes sociales, como en páginas de alto impacto para el mercado peruano (como El Comercio). Esto se detallará en el contenido de Marketing directo y digital. Además de acciones de CDM, como mailings a potenciales clientes y push notifications. 
Figura 3.18

Ejemplo Push Notification

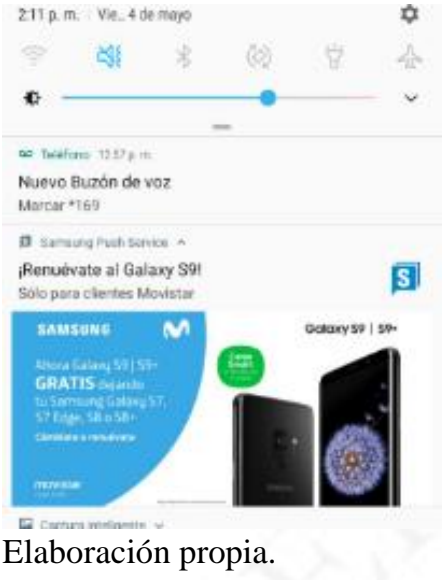

En cuanto a los medios BTL se realizaron con las siguientes acciones:

- Activaciones: Equipos de 3 a 4 personas ubicados cerca a las tiendas propias de Samsung, en la zona de celulares de los retailers y en los operadores, los cuales informaban acerca de las características del celular y demostraban las aplicaciones como el Slow-motion y el AR Emoji. 
Figura 3.19

Activación BTL

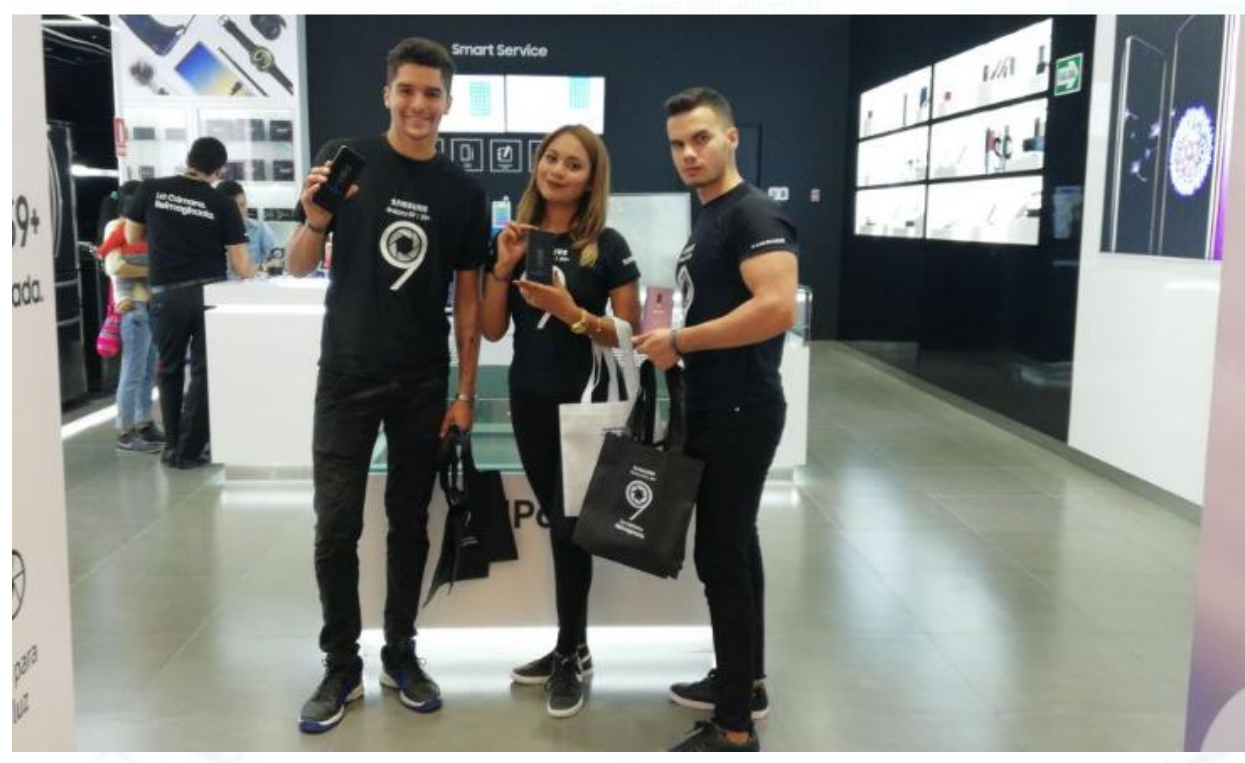

Elaboración propia

○ Evento de Lanzamiento: El día 04 de Abril se realizó un evento de lanzamiento de la marca, donde se presentó el celular a los medios y a los clientes.

- Medios Digitales

Kotler y Armostrong (2017, pág. 366), definen al marketing directo y digital como "marketing encaminado a comprometerse de manera directa con consumidores individuales y comunidades de clientes seleccionados cuidadosamente, tanto para obtener una respuesta inmediata como para forjar relaciones duraderas con ellos.

○ Redes Sociales: Samsung cuenta con una página de Facebook, Twitter e Instagram exclusivamente para Perú. En estas páginas se comunicaron las principales características del celular, fecha de lanzamiento, fecha de los eventos...etc.

- Mailings: Con la información recaudada en redes sociales y en las activaciones, se envió una serie de mailings a los potenciales clientes con información y los beneficios del producto. Además se usó la base de datos de clientes actuales, que tengan celulares de la serie $\mathrm{S}$ y Note anteriores.

- Publicidad SEO y SEM: Se utilizaron las herramientas de SEO (Search Engine Optimization) y SEM (Search Engine Marketing) para poder tener buenos resultados en las búsquedas online, del mismo modo se colocarán anuncios y enlaces patrocinados utilizando Google AdWords. 
○ Página Web: Se creó una página de pre-registro, para los consumidores interesados en el producto, en la cual se registraban para obtener información sobre el producto y las fechas de lanzamiento. Se creó otra página de pre-venta, donde los consumidores interesados podían registrarse para pagar el celular antes de la fecha de lanzamiento y recogerlo el día del lanzamiento. Además, existe una página web con las características detalladas del celular.

- Promoción de Ventas:

- Promoción a los intermediarios: Solo durante las fecha de lanzamiento, se le entrego a los diferentes intermediarios, accesorios junto con los celulares, para que puedan lanzar promociones de lanzamiento hacia sus clientes. Cada Carrier tenía una promoción exclusiva.

Ejemplo: Celular+ cargador portátil, Celular + cover, Celular+ sujetador para el carro.

\section{- Venta Personal}

- La fuerza de ventas fue capacitada con bastante anticipación y con alta intensidad, debido a la naturaleza del producto. La fuerza de venta, está destinada a Carriers o a Venta de celulares desbloqueados, ya que los discursos de venta varían, debido a la existencia de las líneas telefónicas en los carriers. Junto a la fuerza de ventas, se enviaron mercaderistas y promotores de la marca, para asegurarse los planes de visibilidad e impulsar las ventas.

- Relaciones públicas:

○ Notas de prensa: se realizaron notas de prensa cubriendo el evento de lanzamiento y haciendo reseñas sobre el celular, comunicando sus beneficios y características. 
Figura 3.20

Nota de Prensa El Comercio

\section{Smartphone: evaluamos el Galaxy $S 9$ de Samsung $\mid$ FO'TOS Y VIDEO}

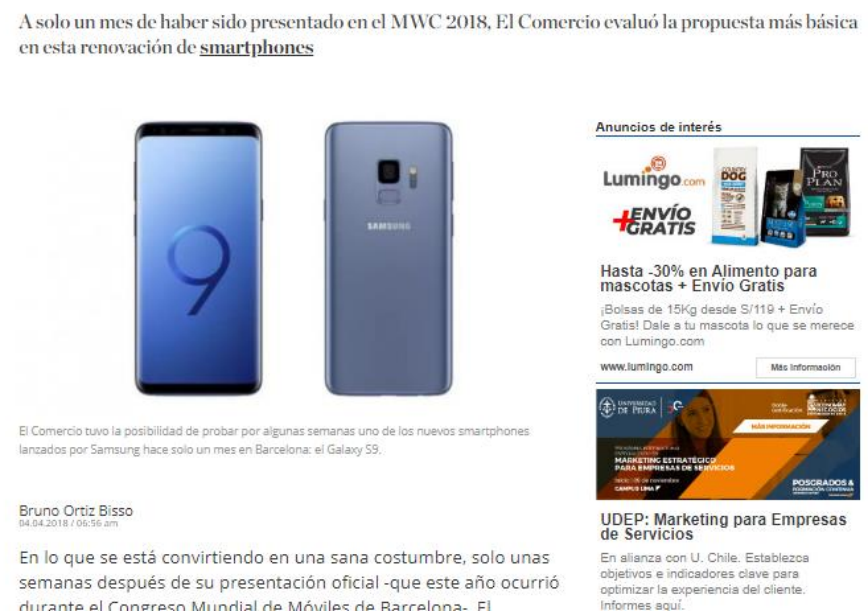

Fuente: El Comercio (2018)

- Publireportajes: en revistas seleccionadas, se realizaron publirreportajes sobre el celular y sus beneficios

○ Evento de lanzamiento: al evento de lanzamiento, se invitó a influencers, periodistas especializados y a prensa en general para que cubran el evento e informen al público sobre el lanzamiento 


\section{CAPITULO IV: ANÁLISIS Y DISCUSIÓN DE RESULTADOS}

Tomando en cuenta la campaña en el rango de abril y junio, con una duración de 8 semanas, el proyecto tuvo objetivos según cada área. Marketing tenía que llegar a mínimo de cobertura, Ventas a un número de unidades y de monto, Logística a cubrir los puntos de venta y Producto a incrementar la participación de mercado. Todos los objetivos del área convergen en 4 puntos básicos para medir la campaña, los cuales se presentarán en el siguiente punto.

\section{Objetivos}

A continuación, se presenta la Tabla 4.1 Objetivos por Área con los objetivos trazados:

Tabla 4.1

Objetivos por Área

\begin{tabular}{|l|l|r|}
\hline Área & Objetivo & Valor \\
\hline Ventas & Unidades & 10,000 \\
\hline Ventas & Ventas & S/. 14,875,000.00 \\
\hline Producto & $\begin{array}{l}\text { Participación de } \\
\text { Mercado }\end{array}$ \\
\hline Logística & Cobertura & $100 \%$ \\
\hline Marketing & Cobertura & $120 \%$ \\
\hline
\end{tabular}

Elaboración propia.

- El área de ventas tuvo como objetivo llegar a 10,000 unidades vendidas y a un monto total de S/.14, 875,000.

- Producto, tuvo que hacer los cálculos correspondientes según los reportes de aduanas para poder estimar el incremento en ventas que signifique el 5\% en el segmento Premium (establecido en los objetivos de ventas)

- Logística tuvo como objetivo llegar a la cobertura total de todos los puntos de ventas reportados como aptos para vender el Galaxy S9|S9+

- Marketing tuvo como principal tarea la cobertura de los puntos establecidos anualmente y además conseguir un esfuerzo del $20 \%$ adicional durante la duración de la campaña

Los 4 objetivos principales de la campaña fueron: 
1. Obtener un ROI\% no menor a $30 \%$

2. Incrementar la participación de mercado en $5 \%$

3. Incrementar la demanda del público femenino en $20 \%$

4. Llegar al objetivo de ventas 10,000 unidades.

\section{Resultados}

- En cuanto a los objetivos por Área se llegó a la meta en todos los casos, menos en el objetivo de unidades. Si bien se vendieron más unidades que el número estimado, se llegó al $85 \%$ de venta en el caso del S9 y al 160\% de unidades del S9+. Lo cual se tradujo en una venta de $S / .17,331,250$, es decir, $17 \%$ más de lo esperado.

- En el caso de producto, se llegó a la estimación correspondiente antes de que pudiera empezar la campaña. El aumento en ventas y en unidades, ayudo a que se incremente en un $5.6 \%$ la participación.

- Logística alcanzo, luego de 18 días el $100 \%$ de la cobertura total de los puntos de venta. El retraso, fue debido a falta de comunicación interna de los clientes, algunos puntos de venta en provincia y el hecho de la falta de stock del S9+, el cual tuvo que volver a proyectarse para poder alcanzar los puntos de venta.

- En cuanto a los esfuerzos de Marketing, hubo 2 puntos que tuvieron un retraso de 5 días, dentro de los elementos anuales. Debido a faltas de coordinación de la agencia publicitaria. Los materiales para Radio, TV, Impresos y Digital no tuvieron inconvenientes. La cuota del $20 \%$ extra por campaña se obtuvo gracias a la compra de 4 elementos en 1 mall nuevo y 3 mall's actuales, así como las menciones y spots en programas como Mujeres Sin filtro, Futbol en América (TV), Mal elemento (Radio) y cobertura full day de Publimetro. 
Tabla 4.2

Resultados según objetivos

\begin{tabular}{|l|l|r|r|}
\hline Área & Objetivo & Valor & \multicolumn{2}{|l|}{ Resultado } \\
\hline Ventas & Unidades & 10,000 & 11,500 \\
\hline Ventas & Ventas & S/. 14,875,000.00 & S/. 17,331,250.00 \\
\hline Producto & $\begin{array}{l}\text { Participación de } \\
\text { Mercado }\end{array}$ & $5 \%$ & $5.6 \%$ \\
\hline Logística & Cobertura & $100 \%$ & $100 \%$ \\
\hline Marketing & Cobertura & $120 \%$ & $125 \%$ \\
\hline
\end{tabular}

Elaboración propia

En cuanto a los objetivos generales de la campaña

1. Obtener un ROI\% no menor a 30\%: Considerando el aumento de ventas y teniendo en cuenta los sobrecostos originados por el sobrestock del S9 y la falta de stock del S9+, se pudo llegar a un $32 \%$ de ROI.

2. Incrementar la participación de mercado en 5\%: Según los reportes del área de producto, la participación en el segmento Premium aumento en 5.6\%

3. Incrementar la demanda del público femenino en $20 \%$ : Según los reportes del área de producto la demanda del público femenino logro aumentar en un $25 \%$

4. Llegar al objetivo de ventas 10,000 unidades: Se logró superar el objetivo de ventas. Sin embargo, en las unidades vendidas se presentaron 2 problemas de consideración: se vendieron menos S9 y más S9+ de lo esperado. Del mismo modo, el incremento del 25\% de la demanda femenina, acelero la venta de las unidades de color morado y no despego tanto la venta de los modelos Midnight Black y Titanium Grey.

\section{Análisis de los resultados de la campaña.}

Si bien los resultados fueron positivos, faltaron detalles en la planificación de la demanda por modelo y por color. Junto a la fuerte comunicación que se realizó para poder captar al público femenino, el cual opto por el modelo morado y orientar la compra al modelo S9+, se presentaron bastantes inconvenientes en ciertos puntos de venta, para poder cumplir con el stock mínimo de unidades, sobre todo los S9+ Lilac Purple. Esto genero molestias en los clientes y en los intermediarios. 
Además de haber cumplido con una planificación adecuada, el ROI podría haber incrementado considerablemente, ya que al tener sobrestock se incurren en gastos de almacenamiento y al quebrar en stock, hay que acelerar la cadena de suministro. Lo cual tiene un costo bastante alto, debido a los costos adicionales de transporte que se tienen que pagar. Por otro lado, el aumento de la demanda del celular morado, lo cual se puede traducir en un aumento de demanda femenina, también podría haber sido mayor. Debido a que clientes pertenecientes al público femenino, no pudieron comprar el modelo morado y prefirieron esperar o no comprar otro modelo de Galaxy $\mathrm{S} 9 \mid \mathrm{S} 9+$. Otro punto importante, fue que al no haber mucha diferencia de precio entre el modelo S9 y S9+, de acuerdo al valor percibido, los clientes optaron por comprar el S9+. Ya que el valor percibido del S9+ era mayor a la diferencia monetaria de S/.500, lo cual se refleja en el $60 \%$ de aumento del objetivo trazado para el S9+ y el 15\% faltante del S9.

\section{Oportunidades de Mejora para la campaña}

1. Distribución exclusiva de los modelos Midnight Black y Titatium Grey por cliente: El foco de la campaña, eran las mujeres de 25 a 55 años, para poder ganar territorio en las usuarias de Smartphones. En el Perú, la tendencia define, que los hombres son mayormente quienes compran los celulares (ya sea para ellos o para sus esposas o hijas). Al ofrecer una alternativa más femenina, se le daba la opción a las mujeres de ser las compradoras o las decisoras de compra. Sin embargo, se descuidó la comunicación de los otros 2 modelos. Por lo tanto, se le podría haber ofrecido a un $50 \%$ de los intermediarios, de acuerdo al poder de negociación de los mismos, los 3 modelos (morado, negro y gris), a un 30\% de los intermediarios los modelos morado y negro y a un $20 \%$ de los intermediarios los modelos negro y gris. Otra alternativa, aparte de distribuir solo modelos exclusivos por cliente, pudo haber sido venderles en mayor proporción el morado y en menor proporción el gris. Es decir dividir la proporción en $50 \%$ morado, $30 \%$ negro y $20 \%$ gris. Dado que si el gris se hubiera acabado más rápido, la siguiente opción hubiera sido el celular negro, el cual tiene mayor aceptación entre ambos sexos.

2. Comunicación más equitativa entre el modelo $S 9$ y $S 9+$ y los colores morado, negro y gris: La comunicación del Galaxy S9|S9+, estuvo centrada en el modelo S9+ y en el color morado. 
Ejemplos:

Figura 4.1

Ejemplo ATL

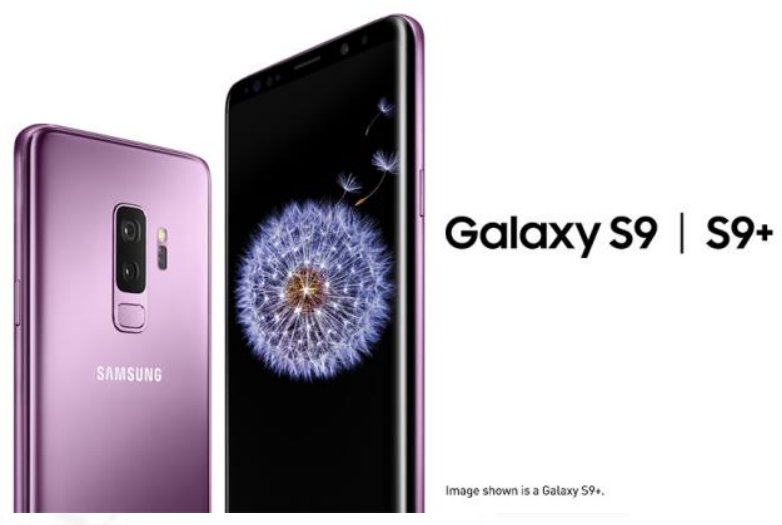

Fuente: Samsung (2018).

Figura 4.2

Ejemplo Spot TV

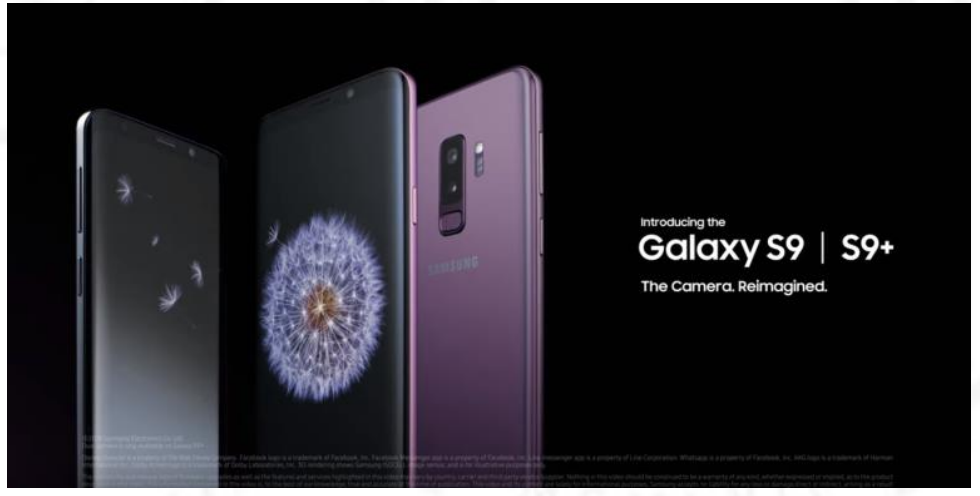

Fuente: Samsung (2018).

$\mathrm{Si}$, bien existe también publicidad dedicada a los 3 colores, esta solo se daba en ocasiones donde el espacio publicitario era de gran extensión en la vía pública. Lo cual en Perú solo se dio en el caso del Jockey Plaza y Real Plaza Salaverry. 
Figura 4.3

\section{Ejemplo $\mathrm{OOH}$}

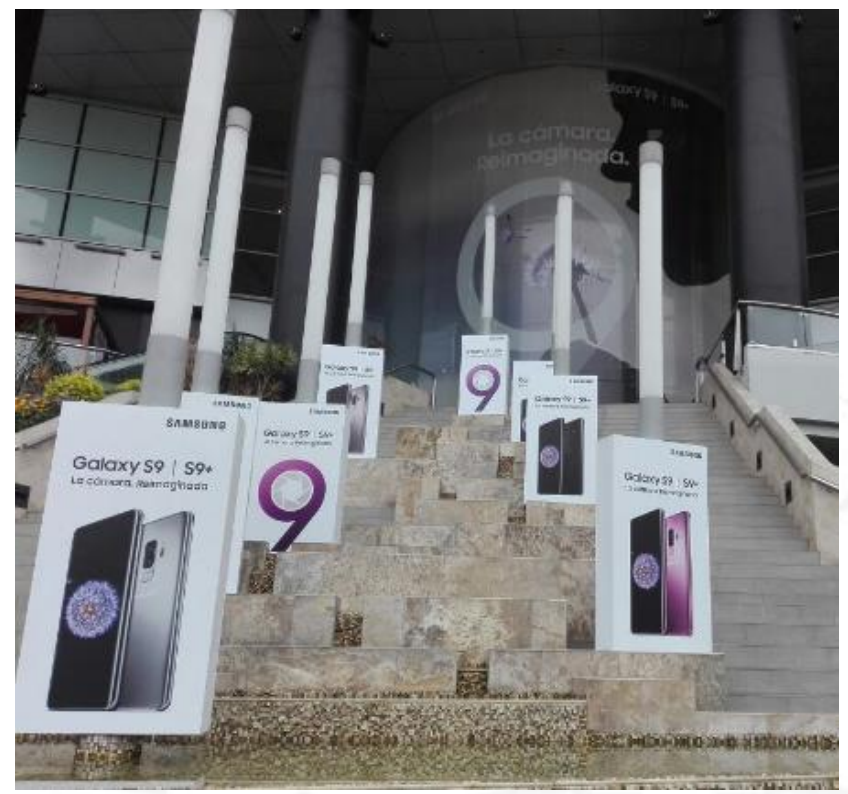

Elaboración propia

Como mencionan Stanton, Etzel y Walker (2007), una de las funciones de la promoción, es Informar acerca del producto. Lo cual en este caso, puede haber fallado llevando a los clientes a pensar que el Galaxy S9|S9+ solo existía en su versión Lilac Purple.

3. Aumentar la diferencia de precio entre los modelos $\mathrm{S} 9$ y S9+: La diferencia de precio entre el S9+ y el S9 era de S/ 500. La principal diferencia entre el S9+ y el S9, era la doble cámara en el modelo S9+ y 2GB de RAM adicionales, aparte de las diferencias que existan entre los modelos $\mathrm{S}$ y $\mathrm{S}+$ anteriores, como mayor capacidad de batería y pantalla de mayor tamaño. La cámara es una característica esencial para el Smartphone y es parte del Hardware, lo que significa que la diferencia de una cámara doble frente a una cámara única es visible a simple vista. En un celular de alta gama, se espera que la cámara se significativamente mejor que otros celulares de menor gama, por lo cual una persona que está dispuesta a pagar más de S/.3,000 está buscando la mejor cámara en su Smartphone. Aunque la diferencia de ambos modelos, solo radica en una función de fotos (fotos con enfoque dinámico), un usuario común podría pensar que 2 cámaras son mucho mejor que una. Por eso el valor percibido del Galaxy S9+, es mayor a S/. 500 soles de diferencia con el S9. Por lo tanto el S9, se podría ofrecer a S/.2900 y el S9+ a S/. 2700. 
4. Considerar el aumento de la demanda femenina a la hora de hacer la estimación de la demanda: Como se ha mencionado anteriormente, el foco de la campaña estuvo en los modelos de color morado. Por lo tanto se debió prever un aumento mayor a $20 \%$ de la demanda femenina, para poder contar con un stock suficiente que pueda satisfacer las necesidades de los consumidores. 


\section{CONCLUSIONES}

- La campaña de Galaxy S9|S9+ se llevó acabo en Perú, durante los meses de marzo y junio según los tiempos esperados. Los segmentos objetivos fueron los hombres y mujeres de NSE A, B y C, de 25 a 55 años. Sin embargo, la comunicación se centró en las mujeres de este mismo grupo.

- Se cumplieron los objetivos trazados inicialmente, sin embargo hubo una diferencia de ventas significativa entre lo proyectado para el S9 y el S9+.

- La campaña tuvo mejores resultados que la de su predecesor el Galaxy S8|S8+

- Samsung sigue siendo el líder indiscutible en el mercado de celulares, sin embargo en el sector Premium, existe otro competidor importante aparte de IPhone, los celulares Huawei, quienes con una estrategia de precios bajos están ganando participación a grandes pasos. 


\section{REFERENCIAS}

Ansoff, H.I. (1957). Strategies for diversification. Massachusetts: Harvard Business Review

Czinkota, M. y Kotabe, M. (2001). Marketing Management. Cincinnati: South-Western College

Compañía Peruana de Estudios de Mercado y Opinión Pública (CPI). (Octubre 2017). Evolución Del Mercado De Smartphone Y Smart Tv En El Perú [versión PDF]. Recuperado de images/upload/paginaweb/archivo/26/mr_tenencia_smartphone_smarttv_2017.pdf

Ferrel, O.C. y Hartline, M. (2018). Estrategia de Marketing. México D.F.: Cengage Learning Editores.

Keller, K y Lane, K. (2013). Strategic Brand Management. Boston: Pearson Education.

Kotler, P. y Armstrong, G. (2013). Fundamentos de Marketing. México D.F.: Pearson Education.

Kotler, P. y Armstrong, G. (2016). Principles of Marketing. Boston: Pearson Education.

Kotler, P. y Keller, K. (2016). Dirección de Marketing. México D.F.: Pearson Education.

Nores, I. (24 de enero de 2018). Penetración de smartphones en Perú casi se triplicó en últimos cuatro años [redacción]. Diario Gestión. Recuperado de: https://gestion.pe/economia/empresas/penetracion-smartphones-peru-triplico-ultimoscuatro-anos-225607

Organismo Supervisor de Inversión Privada en Telecomunicaciones (OSIPTEL). (2018). Investigaciones Recuperado de https://www.osiptel.gob.pe/documentos/investigaciones

Ortiz, B. (04.04.2018). Smartphone: evaluamos el Galaxy S9 de Samsung Recuperado de: https://elcomercio.pe/tecnologia/moviles/smartphones-evaluamos-galaxy-s9-samsungnoticia-509094

Samsung Perú (2018). Samsung S9|S9+. Recuperado de: https://www.samsung.com/pe/smartphones/galaxy-s9/

Stanton, W., Etzel, M. y Walker, B. (2007). Fundamentos de Marketing. México D.F.: McGraw-Hill Interamericana Editores S.A. 
ANEXOS 
Anexo 1.

Perfil del Smartphonero realizado por IPSOS 2017

\section{Perfil del Smartphonero}

- Tenencia de Smartphone por ámbito

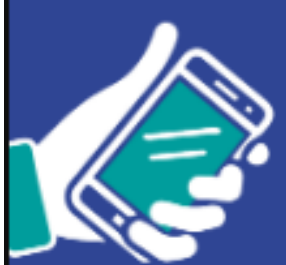

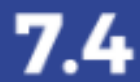

millones de personas
$.23 \%$

- en el Perú

enel Peru
$30 \%$

en el Perú Urbano
$40 \%$

de 12 a 70 años en el Perú Urbano

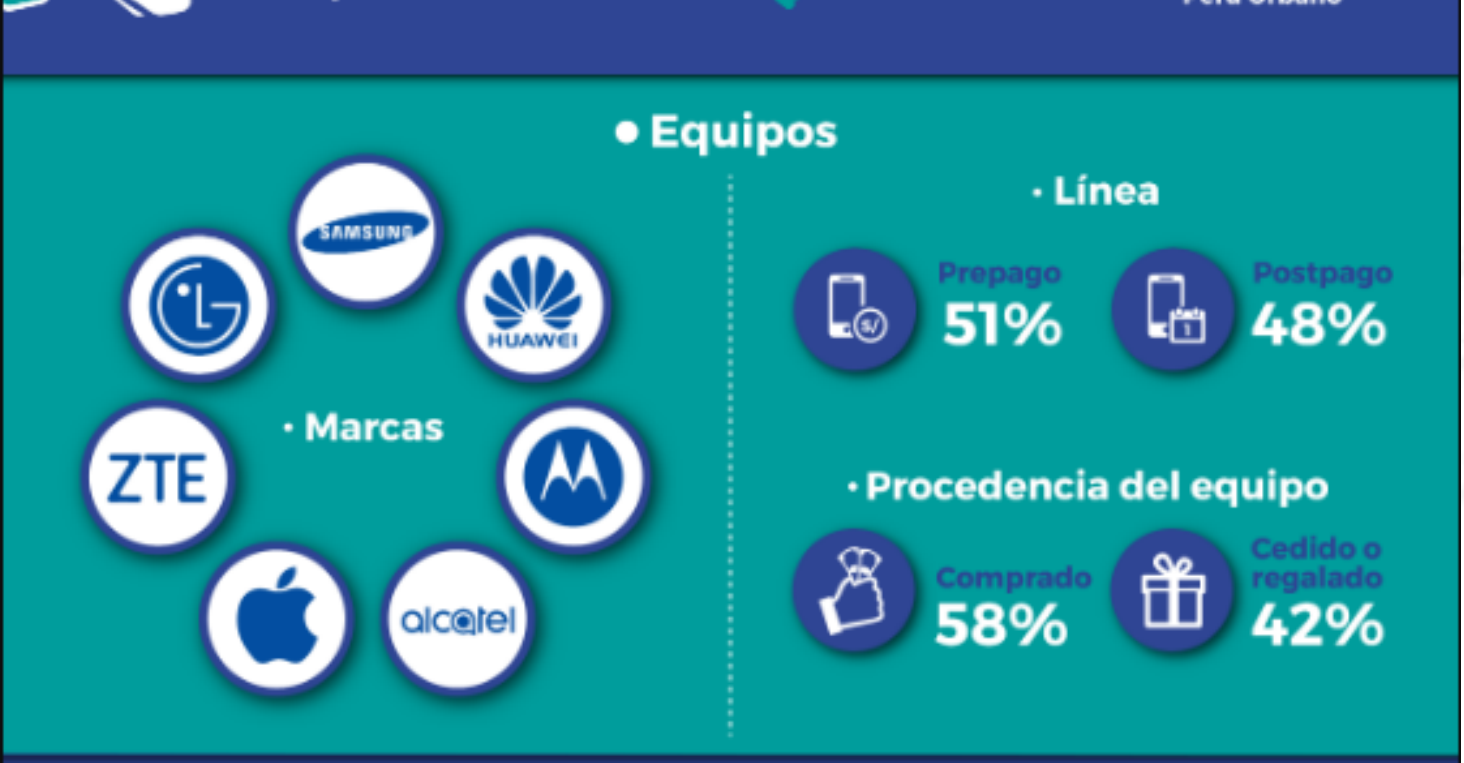




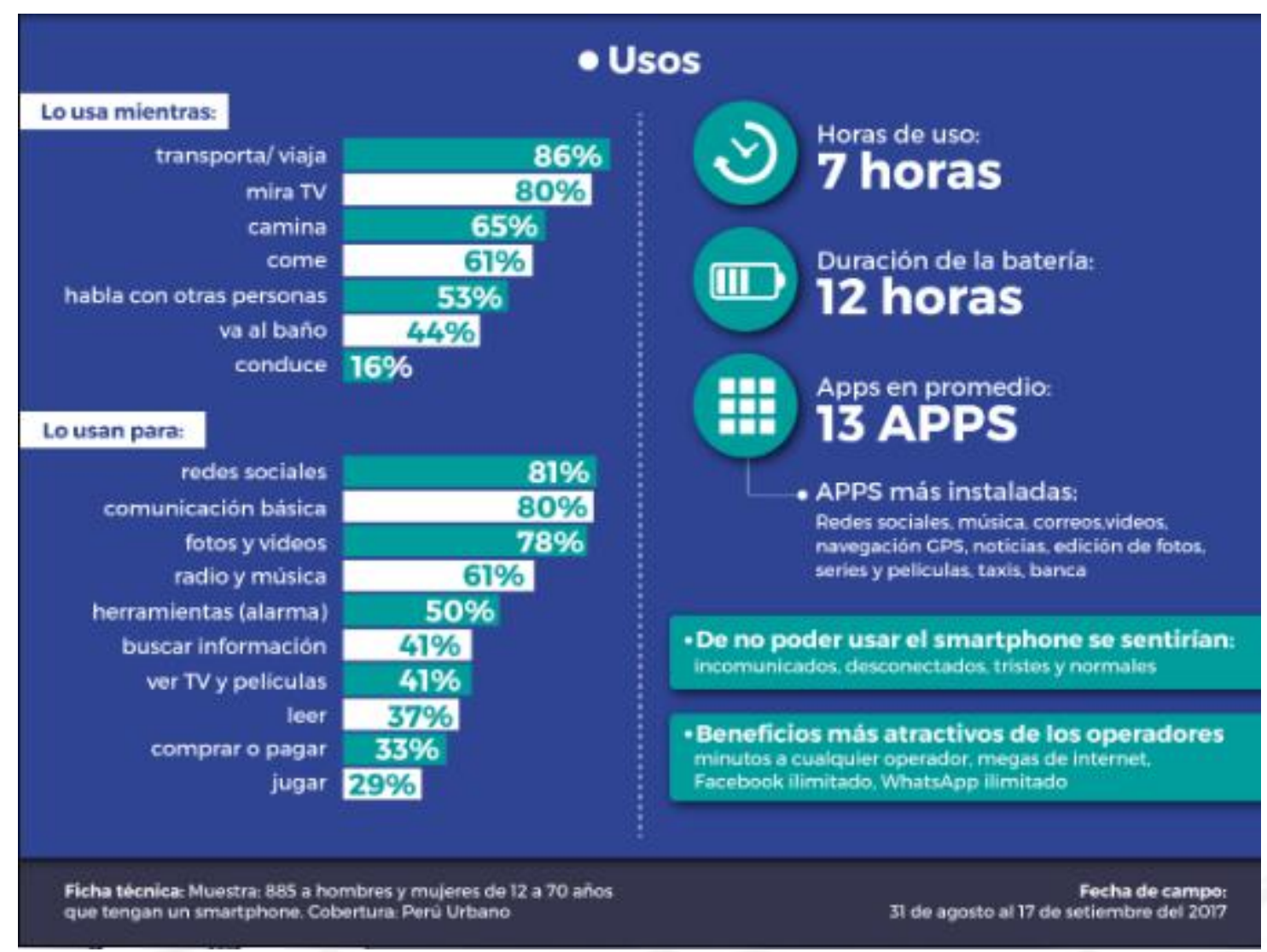


Anexo 2

Reporte de Mercado Smartphones por CPI

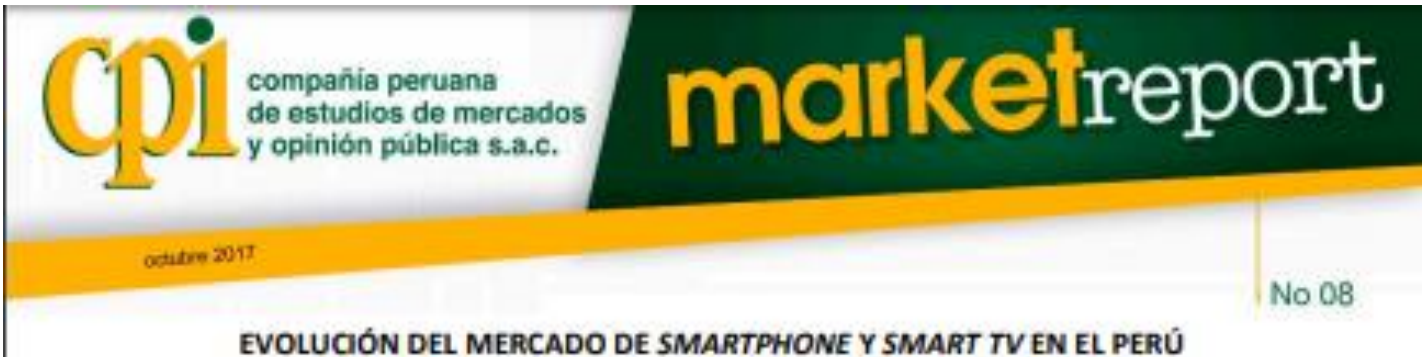

SMARTPHONE

Considerando los tres útimos antos, 2015-2017, observames que el crecimiento en la tenencia de Smartphone en hagares ha sido de tipo exponencial a nivel Penú. Así tenemos que este tipo de celulares han crecido a nive nacional $148 \%$ en estos útimos tres antos, según musstra encuesta anual realizada a nivel nacional en 4251 hogares.

El crecimiento es alto a nivel nacional: para el $A B$ con un $61 \%$, en ef $C$ con $140 \%$, $y$ en el DE con $253 \%$ en los ütimos tres anos.
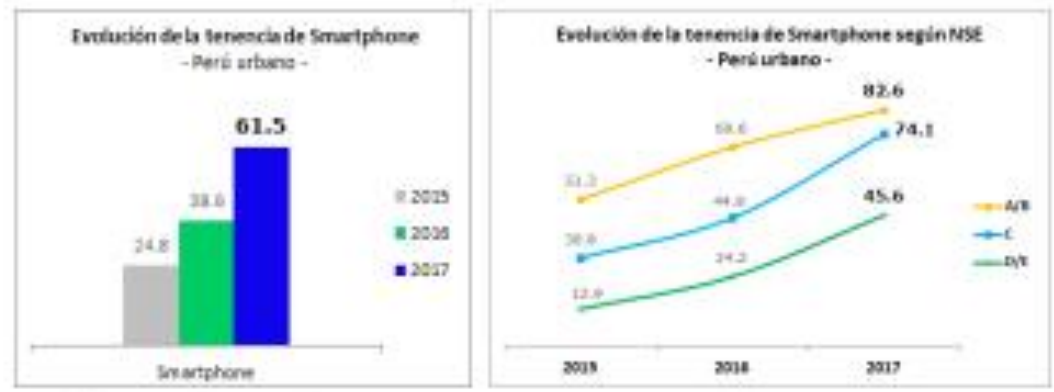

Paradojicamente los Smartphane tienen un mayor crecimiento en los hogares DE: en Lima $427 \%$ y en el interior 216\%. La principal razón de este alto aumento es el imterts de las personas por contar con internet en sas celulares y, por otro lado, el abaratamiento de los equipos por ef ingreso de nuevas empresas al mercado.

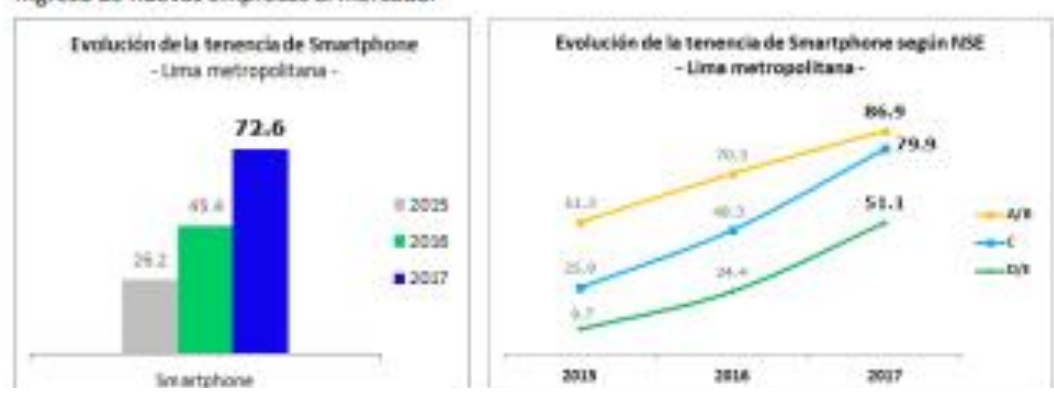

compañila peruana de estudios de mercados y opinión pública s.a.c.

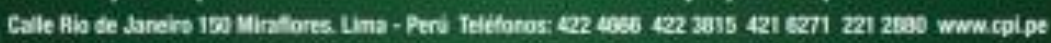

